\title{
THE
}

2009

\section{Manifestation of the Pacific Decadal Oscillation in the Kuroshio}

\author{
Magdalena Andres \\ University of Rhode Island \\ Jae-Hun Park \\ University of Rhode Island \\ Mark Wimbush \\ University of Rhode Island, mwimbush@uri.edu \\ Xiao-Hua Zhu \\ Hirohiko Nakamura
}

See next page for additional authors

Follow this and additional works at: https://digitalcommons.uri.edu/gsofacpubs

Terms of Use

All rights reserved under copyright.

\section{Citation/Publisher Attribution}

Andres, M., Park, J.-H., Wimbush, M., Zhu, X.-H., Nakamura, H., Kim, K., and Chang, K.-I. ( 2009), Manifestation of the Pacific Decadal Oscillation in the Kuroshio, Geophys. Res. Lett., 36, L16602, doi:10.1029/2009GL039216.

Available at: https://doi.org/10.1029/2009GL039216

This Article is brought to you for free and open access by the Graduate School of Oceanography at DigitalCommons@URI. It has been accepted for inclusion in Graduate School of Oceanography Faculty Publications by an authorized administrator of DigitalCommons@URI. For more information, please contact digitalcommons-group@uri.edu. 


\section{Authors}

Magdalena Andres, Jae-Hun Park, Mark Wimbush, Xiao-Hua Zhu, Hirohiko Nakamura, Kuh Kim, and Kyung-II Chang

This article is available at DigitalCommons@URI: https://digitalcommons.uri.edu/gsofacpubs/629 
$\begin{array}{llll}\text { GEOFIZIKA } & \text { VOL. } 26 & \text { No. } 2 & 2009\end{array}$

\title{
North Adriatic tides: observations, variational data assimilation modeling, and linear tide dynamics
}

\author{
Jeffrey W. Book ${ }^{1}$, Henry Perkins ${ }^{2}$ and Mark Wimbush ${ }^{3}$ \\ 1 Naval Research Laboratory, Stennis Space Center, U.S.A. \\ 2 University of Maine, Darling Marine Center, Walpole, U.S.A \\ 3 University of Rhode Island, Graduate School of Oceanography, Narragansett, U.S.A
}

Received 17 June 2009, in final form 9 December 2009

\begin{abstract}
Fifteen open-sea time-series observations of tidal velocities and tidal bottom pressures for more than six months duration provide a new database for North Adriatic tides. The observations show nearly reversing tidal currents at most locations and increasing tidal-current strength near Istria. Tidal elevation amplitudes and phases respectively increase northwestward and counterclockwise, strongly for semidiurnal tides and weakly for diurnal tides. The data are used for optimal determination of boundary conditions for a linear strong-constraint variational data assimilation model and the resulting average rms difference errors for tidal elevations and currents are below $1 \mathrm{~cm}$ and $0.5 \mathrm{~cm} / \mathrm{s}$, respectively. The $Q$ factors from the model are 14.0 for $M_{2}$ and 22.4 for $K_{1}$, but comparisons between frictional dissipation estimated from the model and from the data suggest that model dissipation values could be too high by a factor of two and $Q$ factors too small. Model potential energy is 1.5 times kinetic energy for $M_{2}$ and 6.1 times kinetic energy for $K_{1}$. Observational and modeling results suggest that energy fluxes from Kvarner Bay are significant in the North Adriatic tidal energy balance. $M_{2}$ energy fluxes support the concept of an incident and reflected Kelvin wave in the North Adriatic with some modification. $K_{1}$ energy fluxes show a northeastward cross-basin flux near the $50 \mathrm{~m}$ isobath where the bathymetric slope is particularly steep, with Kelvin-wave-like structures north of the ridge and departures from Kelvin-wave structure south of the ridge.
\end{abstract}

Keywords: tidal velocity, tidal elevation, tidal dissipation, Kelvin wave, Topographic Rossby wave, energy flux

\section{Introduction}

The Adriatic Sea may be represented roughly as an $800-\mathrm{km}$ long, $150-\mathrm{km}$ wide channel-like-arm of the Mediterranean Sea, oriented southeast-northwest, open at the southeast end (Strait of Otranto), with the bottom sloping upward toward the closed northwest end. For purposes of this paper, we de- 
fine the North Adriatic as the final $200 \mathrm{~km}$ of this "channel" where depths decrease from $70 \mathrm{~m}$ in the southeast to less than $10 \mathrm{~m}$ in the northwest (Figure 1). The southwest side of the basin is characterized by a mild across-axis bathymetry slope and by interruption of the coastline profile by the Po River Delta. In contrast, the northeast side of the basin is characterized by steeper drop-offs at the coast and numerous deep bays and channels. Most of these bays and channels on the northeast side are nearly isolated from the main Adriatic, but Kvarner Bay opens up to the Adriatic through a $30-\mathrm{km}$ wide passage. Vela Vrata Strait, a 5-km wide, $60-\mathrm{m}$ deep passage at the northern end of Kvarner Bay, provides a conduit for exchange of tidal energy between a number of back bays and channels and the main Adriatic.

There has been considerable theoretical and practical research on the tides of the Adriatic (see Cushman-Roisin et al., 2001, for a review), but, as in many coastal areas, direct measurements of tidal currents have been limited by technological and fishing-pressure restrictions. Regarding theory, Hendershott and Speranza (1971) and Mosetti (1986) applied the theory of Taylor (1921) for a tide wave in a channel to explain the semidiurnal tide in the Adriatic as a superposition of an incident and reflected Kelvin wave propagating along the axis of the Adriatic and a set of Poincaré wave modes confined at the head of the basin in a wave reflection zone. Malačič et al. (2000) re-examined this application and also showed the possibility for Topographic Rossby waves (TRWs) to exist in the Adriatic. They showed that the along-axis slope of the Adriatic is more important for diurnal tides of the Adriatic than for semidiurnal tides and used TRWs to explain some characteristic features of these tides in the North Adriatic.

Recent work (Cushman-Roisin and Naimie, 2002; Janeković et al., 2003; Janeković and Kuzmić, 2005; Martin et al., 2006) has focused on using three-dimensional, high-resolution, numerical models with realistic topography to simulate the Adriatic tides, and then validating components of these simulations with available observations. The interaction of stratification and tides in the Adriatic is also presently a topic of investigation, with Chavanne et al. (2007) citing Po River stratification as a possible explanation for model/data discrepancies near the Italian coast and Mihanović et al. (2006) and Mihanović et al. (2009) studying internal tides in the central Adriatic.

Recent mooring measurements from the North Adriatic present a new opportunity to add to the accumulated knowledge of Adriatic tides. Specifically, although many of the modeling studies assimilate sea-surface variations measured at coastal tide stations and some include evaluation of results against tidal velocity data, none of the above studies assimilates either tidal velocity data or sea-surface elevation data from the open sea. Assimilation of velocity data is very useful for constraining the total tidal dynamical solution as the velocity field is typically less horizontally coherent and more sensitive to bathymetry and coastal topography. Also, assimilation of open-ocean sea-surface elevation data is preferable to assimilation of coastal station data because coastal 
station data can be sensitive to the exact gauge location placement and local coastline features not resolvable in larger scale models. Therefore this study uses depth-averaged velocities and bottom pressures, measured from moorings at 15 different open-sea locations spread throughout the North Adriatic for more than six months over the winter of 2002/2003 (Book et al., 2007b), both to describe the depth-averaged tidal dynamics and to assimilate the data into a linear variational data-assimilation model (Griffin and Thompson, 1996). These new observations and model results are then used to examine anew the concepts of Adriatic Kelvin-wave and TRW modes. We use the term "reversing tides" throughout this paper to refer to the special dynamical case when tidal current ellipses have eccentricities equal to one and therefore the currents are reversing (Hicks, 2000).

\section{Measurements}

From September 2002 to May 2003, an array of RD Instruments (RDI) Workhorse Sentinel broadband ADCPs was deployed in the North Adriatic as

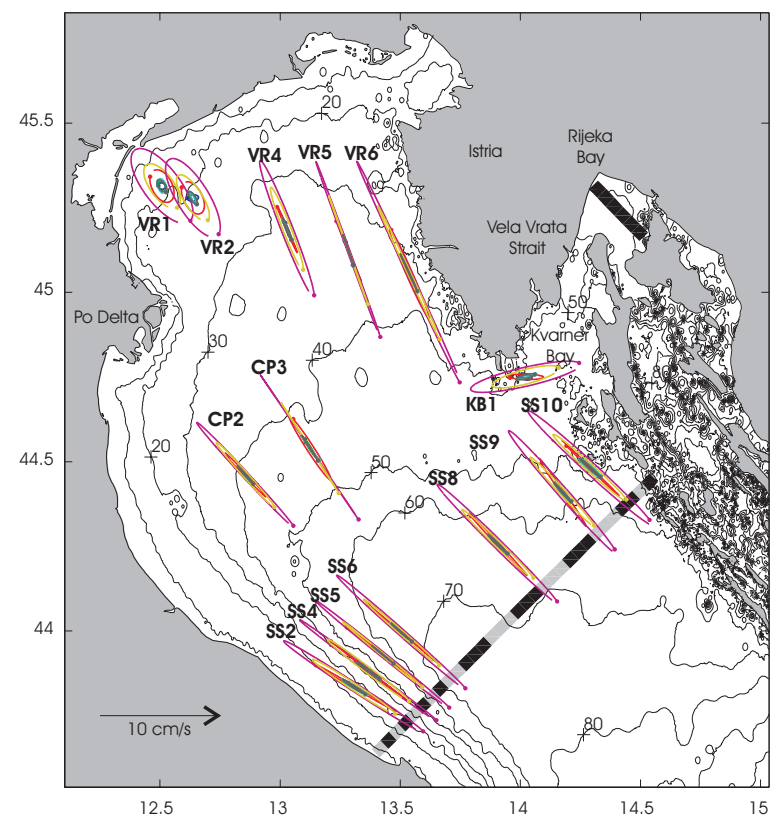

Figure 1. Mooring locations (centers of the ellipses) and tide ellipses from observed vertically-averaged currents. $M_{2}$ ellipses are drawn in magenta, $K_{1}$ in red, $S_{2}$ in yellow, $O_{1}$ in blue, $P_{1}$ in green, $N_{2}$ in cyan, and $K_{2}$ in black. Tidal currents rotate from the dot (time of the transit of the fictitious star, see Foreman, 1978) to the gap. The velocity scale is in the lower-left corner. The model bathymetry is contoured at $10 \mathrm{~m}$ intervals and the model structure functions are shown as alternating dark and light gray bands across the southeastern boundary and in Rijeka Bay. 
part of a Joint Research Project (JRP) between the U.S. Naval Research Laboratory (NRL) and the NATO Undersea Research Centre (NURC). The JRP moorings consisted of 14 trawl-resistant bottom-mounted ADCPs (Perkins et al., 2000) distributed along portions of 4 mooring sections (SS, CP, KB, and VR lines). An additional upward-looking ADCP was mounted near the base of a meteorological tower (Cavaleri, 2000). The mooring positions are shown in Figure 1 and listed in Table 1 with their mean-sea-level depths. The full mooring sections were populated by both these JRP moorings and moorings from several international partners collaborating on the study of the North Adriatic (Lee et al., 2005). In addition to the ADCP measurements of currents throughout the water column, bottom pressure (by ADCP or wave/tide gauge) was also measured at each site. Further details of the mooring instrumentation can be found in Book et al. (2007a). Previously these data were used to study the vertical structure of the bottom tidal flows (Book et al., 2009).

\subsection{Tidal analysis}

The JRP ADCPs were set to measure the currents using $62-90 \mathrm{~s}$ bursts of pings at a $1 \mathrm{~Hz}$ rate every 15 minutes, except for the first half of the VR 1 deployment which used 16 minute bursts of pings at a $0.5 \mathrm{~Hz}$ rate every hour. Book et al. (2007a) described quality-control steps used to exclude bad data. Despite the lack of any physical evidence of instrument malfunction, orientation disagreements of station VR5 observed tidal ellipses with those from

Table 1. Mooring positions and depths.

\begin{tabular}{cccc}
\hline Mooring & Latitude & Longitude & Depth $(\mathrm{m})$ \\
\hline SS2 & $43.8351^{\circ} \mathrm{N}$ & $13.3066^{\circ} \mathrm{E}$ & 25 \\
SS4 & $43.8836^{\circ} \mathrm{N}$ & $13.3667^{\circ} \mathrm{E}$ & 46 \\
SS5 & $43.9307^{\circ} \mathrm{N}$ & $13.4261^{\circ} \mathrm{E}$ & 57 \\
SS6 & $43.9956^{\circ} \mathrm{N}$ & $13.5044^{\circ} \mathrm{E}$ & 66 \\
SS8 & $44.2567^{\circ} \mathrm{N}$ & $13.9053^{\circ} \mathrm{E}$ & 65 \\
SS9 & $44.4102^{\circ} \mathrm{N}$ & $14.1748^{\circ} \mathrm{E}$ & 59 \\
$\mathrm{SS} 10$ & $44.4812^{\circ} \mathrm{N}$ & $14.2904^{\circ} \mathrm{E}$ & 51 \\
$\mathrm{CP} 2$ & $44.4610^{\circ} \mathrm{N}$ & $12.8551^{\circ} \mathrm{E}$ & 42 \\
$\mathrm{CP} 3$ & $44.5402^{\circ} \mathrm{N}$ & $13.1245^{\circ} \mathrm{E}$ & 42 \\
$\mathrm{~KB} 1$ & $44.7507^{\circ} \mathrm{N}$ & $14.0213^{\circ} \mathrm{E}$ & 48 \\
VR1 & $45.3139^{\circ} \mathrm{N}$ & $12.5081^{\circ} \mathrm{E}$ & 17 \\
VR2 & $45.2789^{\circ} \mathrm{N}$ & $12.6370^{\circ} \mathrm{E}$ & 25 \\
VR4 & $45.1878^{\circ} \mathrm{N}$ & $13.0281^{\circ} \mathrm{E}$ & 33 \\
VR5 & $45.1249^{\circ} \mathrm{N}$ & $13.2837^{\circ} \mathrm{E}$ & 35 \\
VR6 & $45.0581^{\circ} \mathrm{N}$ & $13.5360^{\circ} \mathrm{E}$ & 33 \\
\hline
\end{tabular}


neighboring ADCP sites and with three independent modeling simulations (Janeković and Kuzmić, 2005; Martin et al., 2006; and this paper) strongly suggest a compass error is present in the VR5 data. Therefore, the recorded currents at site VR5 were rotated $28^{\circ}$ clockwise to align with the data-assimilation modeling predictions of this paper.

Vertically-averaged tidal currents were calculated by taking the depth means (neglecting values flagged as bad) of the observed ADCP currents and using the Response Method of Munk and Cartwright (1966) on the 15-minute current ensemble time series (time values assigned to the center time of the measurement bursts). The mean was computed only for the portion of the water column measured by the ADCPs, i.e., no corrections were made to account for the possible effect on the mean by the bottom ( $2.5 \mathrm{~m}$ or less) or top (4 $\mathrm{m}$ or less) portions of the water column. Slightly different procedures, described in Book et al. (2007a), were used to calculate tidal currents at site VR1 to account for the change in ADCP settings midway through the deployment. The Response Method was used both to obtain pure tidal time series and to estimate the harmonic tidal coefficients for the $O_{1}, P_{1}, K_{1}, N_{2}, M_{2}, S_{2}$, and $K_{2}$ constituents.

Bottom pressure fluctuations were measured by Sea-Bird Electronics, SBE26 Seagauge Wave \& Tide Recorders (WTRs) at all sites except SS4, SS10, and VR1. The WTRs were set to average pressure continuously over 20 minutes and produce time series of bottom pressure at this interval. At sites SS4 and SS10 and during the second portion of the site VR1 deployment, pressure was measured by the ADCPs. ADCP pressure measurement settings were identical to the velocity measurement settings. Each resulting pressure time series, whether from WTR or ADCP, was converted to sea-surface elevation by dividing by the gravitational acceleration and by the density estimated using the measured temperature and a constant salinity of $38.2 \mathrm{psu}$. The Response Method was used to determine the tidal portion of these time series. No gaps or problems were noted in any of these time series and, therefore, no quality control procedures were applied. Atmospheric pressure tides were not removed from the bottom pressure records because the degree to which the inverted barometer effect compensated for these pressure fluctuations was unknown. However, their impact is estimated to be negligible given that the maximum amplitude for $M_{2}$ from atmospheric pressure records on nearby gas platforms was less than $0.5 \mathrm{~cm}$ and much of this should be inverted-barometer compensated.

Throughout the paper, we will make use of a rotary coefficient to describe the rotational direction and eccentricity of tidal ellipses. The rotary coefficient as defined by Gonella (1972) can be expressed in terms of tidal ellipse parameters as

$$
C_{R}=\frac{-2 A_{1} A_{2}}{A_{1}^{2}+A_{2}^{2}}
$$


where $A_{1}$ and $A_{2}$ are the semi-major and semi-minor ellipse axes, respectively, with the semi-minor axis given a negative value for clockwise rotation of the tidal current vectors by convention (Foreman, 1978). Thus the sign of $C_{\mathrm{R}}$ is opposite to that of the semi-minor axis (by this convention) and is positive for clockwise rotation of the tidal vector, negative for counterclockwise rotation of the tidal vector, and zero for reversing tides.

\subsection{Tidal observations}

The tidal ellipse parameters calculated from the observed vertically-averaged currents are given in Tables 2 and 3, and the resulting tidal ellipses are shown in Figure 1. Eccentricity is high ( $>0.98$, i.e., nearly reversing tidal currents) and currents are aligned along the Adriatic along-axis direction for all constituents and at all sites except for KB1 in Kvarner Bay and VR1 and VR2 in the northwest corner. There is an increase in tidal currents near the Istrian coast; site VR6 had the strongest tidal current with an $M_{2}$ semi-major axis of $10 \mathrm{~cm} / \mathrm{s} . M_{2}$ tidal currents are strongest at all sites (average semi-major axis 7 $\mathrm{cm} / \mathrm{s}$ ), but $S_{2}$ and $K_{1}$ tidal currents also play prominent roles (average semi-major axes $4 \mathrm{~cm} / \mathrm{s}$ and $3 \mathrm{~cm} / \mathrm{s}$, respectively). $O_{1}, P_{1}, N_{2}$, and $K_{2}$ are all much weaker with average semi-major axes of $1 \mathrm{~cm} / \mathrm{s}$.

These lesser constituent ellipses closely match scaled-down versions of the respective dominant diurnal or semidiurnal constituent ellipses in amplitudes, orientations, and phases. i.e., $P_{1}$ vertically-averaged tidal currents match $K_{1}$ currents at one third the strength, and $N_{2}$ and $K_{2}$ currents match $M_{2}$ currents at one sixth the strength. These ratios are close to those for the equilibrium-tide forcing ( $1 / 3$ for $P_{1} / K_{1}, 1 / 5.2$ for $N_{2} / M_{2}$, and $1 / 7.9$ for $\left.K_{2} / M_{2}\right) . O_{1}$ is an exception to this trend with ellipses that do not always closely scale with $K_{1}$ ellipses.

The tidal elevation amplitudes and phases calculated from the observed bottom pressures are given in Tables 4 and 5 and shown in Figure 2. The two largest constituents are $K_{1}$ and $M_{2}$, with $K_{1}$ having the largest amplitude at all the mooring sites except those on the VR line where $M_{2}$ amplitudes exceed the $K_{1}$ values. $S_{2}$ has nearly the same amplitude as $O_{1}$ and $P_{1}$ at the SS line, but, like $M_{2}$, has amplitude increasing markedly towards the northwest, reaching values more than double the amplitudes of these lesser diurnal constituents on the VR line. $N_{2}$ and $K_{2}$ amplitudes also share in this semidiurnal constituent pattern of increase towards the northwest but remain smaller at all the mooring sites than those of the other 5 constituents. The diurnal amplitudes also all increase towards the northwest, but the increases are much less pronounced (27-42 \%) than corresponding increases in semidiurnal amplitudes (205-259\%).

The relative flatness of the amplitude curves from SS2 to SS10 indicates that the SS line is nearly a co-range line for all seven constituents. However, the SS line itself is slightly curved (The bearing pivots clockwise from $42^{\circ}$ to 
$51^{\circ}$ True at a center point between SS6 and SS8) and thus the observed semidiurnal amplitude minimums at SS8 (all constituents) would likely be enhanced if the measurements had been done along a straight bearing across the sea. $K_{1}$ and $P_{1}$ minimum amplitudes are at SS10 instead of SS8 and the diur-

Table 2. Tidal-current major semi-axis (semi-maj.) and minor semi-axis (semi-min.) amplitudes, ellipse inclination angles (inc.) and phases (pha.) in $\mathrm{cm} / \mathrm{s}$ and degrees respectively, from the JRP mooring measurements on the SS line (Figure 1). All conventions are those of Foreman (1978). The phases are the Greenwich phase lags and negative minor semi-axis amplitude values indicate clockwise rotation of the tidal current vectors.

\begin{tabular}{|c|c|c|c|c|c|c|c|}
\hline & SS2 & SS4 & SS5 & SS6 & SS8 & SS9 & SS10 \\
\hline$O_{1}$ semi-maj. & 1.06 & 1.11 & 0.99 & 1.05 & 1.07 & 1.03 & 1.01 \\
\hline$O_{1}$ semi-min. & -0.10 & -0.05 & -0.01 & -0.10 & -0.13 & -0.07 & 0.02 \\
\hline$O_{1}$ inc. & 152.9 & 149.8 & 149.0 & 141.1 & 132.7 & 125.3 & 135.4 \\
\hline$O_{1}$ pha. & 301.0 & 313.4 & 312.4 & 310.2 & 326.8 & 319.0 & 311.1 \\
\hline$P_{1}$ semi-maj. & 1.28 & 1.36 & 1.30 & 1.24 & 1.12 & 1.09 & 1.06 \\
\hline$P_{1}$ semi-min. & 0.03 & 0.00 & 0.01 & -0.02 & 0.03 & 0.05 & 0.03 \\
\hline$P_{1}$ inc. & 151.2 & 143.3 & 142.9 & 139.5 & 132.7 & 124.4 & 135.5 \\
\hline$P_{1}$ pha. & 331.3 & 331.3 & 333.3 & 330.5 & 330.9 & 326.4 & 322.7 \\
\hline$K_{1}$ semi-maj. & 4.05 & 4.38 & 4.05 & 3.89 & 3.58 & 3.42 & 3.32 \\
\hline$K_{1}$ semi-min. & 0.09 & -0.02 & 0.03 & -0.01 & 0.10 & 0.15 & 0.07 \\
\hline$K_{1}$ inc. & 150.0 & 142.2 & 142.5 & 139.9 & 133.0 & 124.8 & 136.1 \\
\hline$K_{1}$ pha. & 333.4 & 334.0 & 336.4 & 335.1 & 333.8 & 329.6 & 324.7 \\
\hline$N_{2}$ semi-maj. & 1.24 & 1.21 & 1.19 & 1.24 & 1.20 & 1.16 & 1.23 \\
\hline$N_{2}$ semi-min. & 0.12 & 0.02 & 0.07 & -0.01 & 0.07 & 0.11 & 0.19 \\
\hline$N_{2}$ inc. & 148.4 & 145.0 & 139.9 & 140.7 & 134.2 & 130.2 & 139.1 \\
\hline$N_{2}$ pha. & 166.3 & 173.1 & 171.1 & 169.9 & 169.7 & 161.3 & 157.6 \\
\hline$M_{2}$ semi-maj. & 6.97 & 7.11 & 7.19 & 7.18 & 7.06 & 6.79 & 7.01 \\
\hline$M_{2}$ semi-min. & 0.34 & 0.19 & 0.20 & 0.28 & 0.37 & 0.41 & 0.48 \\
\hline$M_{2}$ inc. & 146.8 & 143.7 & 141.2 & 138.5 & 135.4 & 131.3 & 137.5 \\
\hline$M_{2}$ pha. & 170.2 & 171.2 & 171.0 & 170.3 & 167.0 & 162.1 & 159.4 \\
\hline$S_{2}$ semi-maj. & 4.13 & 4.27 & 4.29 & 4.19 & 4.13 & 3.94 & 4.16 \\
\hline$S_{2}$ semi-min. & 0.27 & 0.25 & 0.11 & 0.17 & 0.24 & 0.25 & 0.31 \\
\hline$S_{2}$ inc. & 146.6 & 142.9 & 140.6 & 138.8 & 136.1 & 132.8 & 137.9 \\
\hline$S_{2}$ pha. & 177.1 & 176.5 & 177.1 & 175.6 & 172.4 & 167.7 & 164.2 \\
\hline$K_{2}$ semi-maj. & 1.14 & 1.18 & 1.19 & 1.16 & 1.14 & 1.09 & 1.15 \\
\hline$K_{2}$ semi-min. & 0.08 & 0.07 & 0.03 & 0.04 & 0.07 & 0.07 & 0.09 \\
\hline$K_{2}$ inc. & 146.7 & 142.9 & 140.4 & 139.0 & 136.1 & 132.9 & 138.1 \\
\hline$K_{2}$ pha. & 177.5 & 177.2 & 177.7 & 176.1 & 173.1 & 168.3 & 164.5 \\
\hline
\end{tabular}


Table 3. As in Table 2, but for JRP mooring measurements on the CP, KB, and VR lines (Figure 1). The superscript ${ }^{\alpha}$ indicates a subtraction of 28 degrees has been applied to these values to account for the inferred (but unexplained) counter-clockwise compass bias in the VR5 measurements (see Section 2.1).

\begin{tabular}{|c|c|c|c|c|c|c|c|c|}
\hline & $\mathrm{CP} 2$ & CP3 & KB1 & VR1 & VR2 & VR4 & VR5 & VR6 \\
\hline$O_{1}$ semi-maj. & 0.79 & 0.87 & 0.55 & 0.30 & 0.46 & 0.60 & 0.89 & 1.16 \\
\hline$O_{1}$ semi-min. & 0.08 & 0.02 & 0.25 & 0.26 & 0.26 & 0.01 & -0.04 & -0.12 \\
\hline$O_{1}$ inc. & 137.9 & 125.3 & 168.5 & 156.7 & 6.4 & 103.3 & $110.7^{\alpha}$ & 114.1 \\
\hline$O_{1}$ pha. & 319.0 & 315.6 & 331.5 & 336.6 & 187.3 & 326.7 & 319.2 & 314.6 \\
\hline$P_{1}$ semi-maj. & 0.80 & 1.01 & 0.47 & 0.47 & 0.46 & 0.69 & 0.89 & 1.29 \\
\hline$P_{1}$ semi-min. & 0.04 & -0.10 & 0.10 & 0.25 & 0.22 & 0.02 & -0.01 & -0.09 \\
\hline$P_{1}$ inc. & 133.5 & 122.6 & 176.5 & 114.1 & 118.5 & 113.3 & $111.8^{\alpha}$ & 113.4 \\
\hline$P_{1}$ pha. & 324.4 & 328.1 & 327.1 & 315.3 & 322.3 & 333.9 & 335.4 & 337.2 \\
\hline$K_{1}$ semi-maj. & 2.50 & 3.17 & 1.51 & 1.46 & 1.45 & 2.16 & 2.80 & 4.12 \\
\hline$K_{1}$ semi-min. & 0.12 & -0.29 & 0.22 & 0.84 & 0.78 & 0.07 & -0.03 & -0.26 \\
\hline$K_{1}$ inc. & 133.4 & 122.9 & 178.5 & 117.1 & 116.8 & 113.3 & $112.5^{\alpha}$ & 113.7 \\
\hline$K_{1}$ pha. & 327.1 & 332.0 & 327.5 & 321.8 & 327.0 & 336.7 & 338.1 & 339.9 \\
\hline$N_{2}$ semi-maj. & 1.05 & 1.27 & 0.86 & 0.64 & 0.63 & 1.05 & 1.32 & 1.76 \\
\hline$N_{2}$ semi-min. & 0.08 & 0.00 & 0.12 & 0.35 & 0.11 & 0.09 & -0.03 & -0.02 \\
\hline$N_{2}$ inc. & 127.7 & 127.2 & 12.8 & 110.6 & 117.8 & 114.4 & $106.1^{\alpha}$ & 112.9 \\
\hline$N_{2}$ pha. & 169.3 & 170.4 & 351.7 & 159.4 & 165.0 & 168.5 & 170.3 & 171.3 \\
\hline$M_{2}$ semi-maj. & 5.95 & 7.33 & 4.68 & 3.75 & 3.76 & 6.08 & 7.84 & 10.23 \\
\hline$M_{2}$ semi-min. & 0.25 & -0.01 & 0.79 & 1.51 & 1.33 & 0.49 & 0.10 & -0.20 \\
\hline$M_{2}$ inc. & 132.8 & 124.2 & 12.9 & 127.5 & 121.7 & 111.4 & $110.1^{\alpha}$ & 115.0 \\
\hline$M_{2}$ pha. & 168.3 & 169.0 & 350.9 & 175.3 & 169.8 & 169.5 & 169.2 & 169.2 \\
\hline$S_{2}$ semi-maj. & 3.62 & 4.46 & 2.87 & 2.19 & 2.23 & 3.68 & 4.82 & 6.12 \\
\hline$S_{2}$ semi-min. & 0.21 & -0.02 & 0.60 & 0.98 & 0.78 & 0.34 & 0.02 & -0.13 \\
\hline$S_{2}$ inc. & 131.8 & 122.6 & 14.7 & 126.3 & 122.6 & 111.1 & $109.8^{\alpha}$ & 115.0 \\
\hline$S_{2}$ pha. & 173.6 & 174.7 & 356.9 & 182.6 & 176.8 & 174.7 & 173.8 & 173.7 \\
\hline$K_{2}$ semi-maj. & 1.01 & 1.24 & 0.80 & 0.60 & 0.61 & 1.02 & 1.34 & 1.70 \\
\hline$K_{2}$ semi-min. & 0.06 & 0.00 & 0.17 & 0.28 & 0.21 & 0.10 & 0.00 & -0.04 \\
\hline$K_{2}$ inc. & 131.3 & 122.6 & 14.8 & 125.3 & 122.1 & 111.3 & $109.5^{\alpha}$ & 114.9 \\
\hline$K_{2}$ pha. & 174.2 & 175.4 & 357.5 & 182.5 & 177.0 & 175.1 & 174.4 & 174.4 \\
\hline
\end{tabular}

nal constituents exhibit less amplitude change $(2-3 \%)$ than the semidiurnal constituents (14-19\%) along this line. The phases for tidal elevation (Figure 2 bottom panel) for both semidiurnal and diurnal constituents all increase (i.e., increasing lag time) counterclockwise across the basin from the northeast coast to the southwest coast. However, semidiurnal phase increases across the 
Table 4. Calculated tidal amplitudes (amp.) and phases (pha.) in cm and degrees respectively, for the JRP moorings on the SS line (Figure 1). The phases are the Greenwich phase lags according to the convention given by Foreman (1977).

\begin{tabular}{lccccccc}
\hline & SS2 & SS4 & SS5 & SS6 & SS8 & SS9 & SS10 \\
\hline$O_{1}$ amp. & 4.20 & 4.17 & 4.13 & 4.12 & 4.07 & 4.08 & 4.10 \\
$O_{1}$ pha. & 48.8 & 53.7 & 47.0 & 45.5 & 38.9 & 34.2 & 35.3 \\
$P_{1}$ amp. & 4.26 & 4.20 & 4.22 & 4.22 & 4.19 & 4.20 & 4.17 \\
$P_{1}$ pha. & 63.4 & 67.3 & 60.9 & 59.2 & 51.7 & 47.0 & 49.2 \\
$K_{1}$ amp. & 13.44 & 13.32 & 13.31 & 13.30 & 13.23 & 13.25 & 13.17 \\
$K_{1}$ pha. & 66.7 & 70.1 & 64.1 & 62.4 & 54.8 & 50.1 & 52.0 \\
$N_{2}$ amp. & 1.44 & 1.41 & 1.34 & 1.31 & 1.29 & 1.41 & 1.54 \\
$N_{2}$ pha. & 277.6 & 280.6 & 270.1 & 264.2 & 237.2 & 221.6 & 222.2 \\
$M_{2}$ amp. & 8.06 & 7.78 & 7.54 & 7.36 & 7.20 & 7.80 & 8.22 \\
$M_{2}$ pha. & 277.5 & 281.6 & 269.6 & 263.8 & 235.3 & 218.5 & 220.4 \\
$S_{2}$ amp. & 4.70 & 4.51 & 4.36 & 4.23 & 4.05 & 4.35 & 4.53 \\
$S_{2}$ pha. & 284.1 & 289.0 & 276.3 & 270.3 & 240.6 & 222.9 & 224.5 \\
$K_{2}$ amp. & 1.30 & 1.25 & 1.21 & 1.17 & 1.12 & 1.20 & 1.25 \\
$K_{2}$ pha. & 284.8 & 289.7 & 277.0 & 271.0 & 241.3 & 223.7 & 225.1 \\
\hline
\end{tabular}
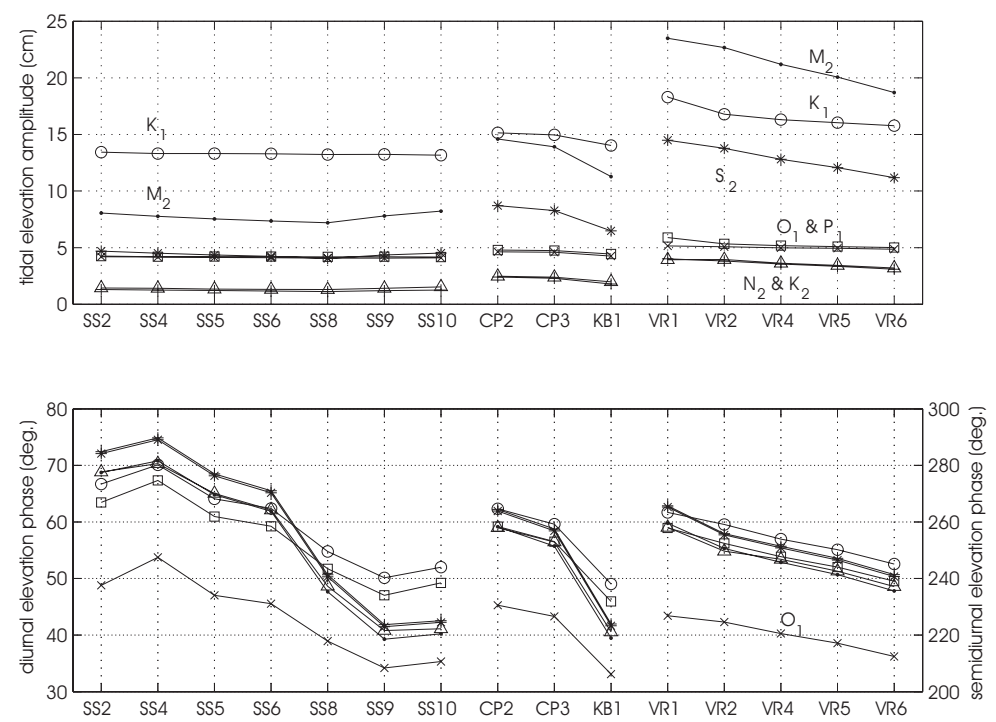

Figure 2. Tidal elevation amplitude in cm (top) and GMT phase lag in degrees (bottom) for each of seven constituents: ॰ for $K_{1}$, ' for $M_{2}$, * for $S_{2}, \times$ for $O_{1}, \square$ for $P_{1}, \triangle$ for $N_{2}$, and + for $K_{2}$. Phase for diurnal constituents is given by the left-hand axis and for semidiurnal constituents by the right-hand axis. The diurnal phases are plotted at double the scale used to plot the semidiurnal phases. 
Table 5. As in Table 4, but for the JRP moorings on the CP, KB, and VR lines (Figure 1).

\begin{tabular}{lcccccccc}
\hline & CP2 & CP3 & KB1 & VR1 & VR2 & VR4 & VR5 & VR6 \\
\hline$O_{1}$ amp. & 4.63 & 4.59 & 4.26 & 5.16 & 5.08 & 4.98 & 4.94 & 4.86 \\
$O_{1}$ pha. & 45.3 & 43.3 & 33.1 & 43.4 & 42.3 & 40.3 & 38.6 & 36.2 \\
$P_{1}$ amp. & 4.80 & 4.74 & 4.44 & 5.90 & 5.33 & 5.18 & 5.10 & 5.01 \\
$P_{1}$ pha. & 59.2 & 56.5 & 45.9 & 58.9 & 56.2 & 53.9 & 52.0 & 49.5 \\
$K_{1}$ amp. & 15.15 & 14.96 & 14.03 & 18.30 & 16.79 & 16.31 & 16.05 & 15.78 \\
$K_{1}$ pha. & 62.3 & 59.6 & 49.0 & 61.7 & 59.5 & 57.0 & 55.1 & 52.6 \\
$N_{2}$ amp. & 2.47 & 2.39 & 1.99 & 3.93 & 3.95 & 3.62 & 3.43 & 3.20 \\
$N_{2}$ pha. & 257.9 & 252.9 & 221.1 & 258.1 & 249.7 & 246.8 & 242.6 & 237.2 \\
$M_{2}$ amp. & 14.60 & 13.91 & 11.27 & 23.50 & 22.69 & 21.21 & 20.07 & 18.72 \\
$M_{2}$ pha. & 258.3 & 251.5 & 218.9 & 259.5 & 250.6 & 245.7 & 241.4 & 235.6 \\
$S_{2}$ amp. & 8.71 & 8.27 & 6.48 & 14.49 & 13.78 & 12.81 & 12.07 & 11.18 \\
$S_{2}$ pha. & 263.9 & 256.8 & 223.3 & 265.2 & 255.4 & 250.8 & 246.5 & 240.7 \\
$K_{2}$ amp. & 2.41 & 2.29 & 1.79 & 4.02 & 3.83 & 3.55 & 3.35 & 3.10 \\
$K_{2}$ pha. & 264.4 & 257.5 & 223.9 & 265.7 & 255.8 & 251.4 & 247.1 & 241.3 \\
\hline
\end{tabular}

basin are 3 times those of the corresponding diurnal phase increases (note the double-scale plotting of diurnal constituent phases in Figure 2).

Qualitatively the trends and values of elevation amplitudes and phases agree with previously published co-tide and co-range charts derived from coastal stations (Polli, 1959, charts reprinted in Cushman-Roisin et al., 2001). Also, as discussed in Malačič et al. (2000), the occurrence of cross-basin elevation amplitude minimums for Adriatic semidiurnal tides in the center of the basin are consistent with the concept of the superposition of an along-axis incident and reflected Kelvin wave.

\section{Linear, variational data-assimilation model}

The model of Griffin and Thompson (1996) was applied to the North Adriatic with data assimilation of the JRP mooring data to determine the proportion of tidal variability that could be described by the shallow water equations, to provide a complete tidal solution for the northern basin, and to investigate tidal energy fluxes and dissipation. This model was applied previously with success to the study of Adriatic tides by Janeković et al. (2003), but their model was set up for the entire Adriatic and assimilated data from 12 coastal tide stations to determine boundary conditions iteratively for a complex three-dimensional finite-element tidal model. Here we instead assimilate open-sea velocity and elevation data and focus on the direct results of the linear shallow-water equation model itself (now run only in the North Adriatic with high 
resolution). Using linear dynamics for our modeling and theoretical work is not a severe limitation for North Adriatic tides due to the predominately linear character of the dynamics; previous studies (Malačič et al., 2000; Cushman-Roisin and Naimie, 2002) have shown that the Adriatic non-linear tidal residual is very small except in a few topographically-complex locations. The model equations are finite-difference forms of the linearized shallow-water equations on an $f$-plane,

$$
\begin{aligned}
& \frac{\partial u}{\partial t}=-g \frac{\partial \eta}{\partial x}+f v-\frac{\lambda}{h} u, \\
& \frac{\partial v}{\partial t}=-g \frac{\partial \eta}{\partial y}-f u-\frac{\lambda}{h} v,
\end{aligned}
$$

and the continuity equation,

$$
\frac{\partial \eta}{\partial t}+\frac{\partial h u}{\partial x}+\frac{\partial h v}{\partial y}=0
$$

where $u$ and $v$ are the northeastward $(x)$ and northwestward $(y)$ velocities, respectively, $h$ is the depth, and $\lambda$ is a linear frictional parameter. A value of $\lambda=5 \cdot 10^{-4} \mathrm{~m} / \mathrm{s}$ was used for the final model run and was found by optimizing over several preliminary runs. Further discussion of optimizing this friction coefficient and the impact on model tidal dissipation is presented in Section 3.2 .

The model was set up with a $45^{\circ}$ counterclockwise rotated Arakawa $\mathrm{C}$ grid using $2-\mathrm{km}$ bathymetric resolution (4-km resolution for $u, v$, and $\eta$ ). The bathymetric grid was derived from the NURC 7.5-second Adriatic database by averaging over $\sqrt{2}-\mathrm{km}$ square blocks and then using nearest-neighbor interpolation to the $2-\mathrm{km}$ tilted square grid. The centers of the tilted grid align with every other diagonal of the finer-resolution untilted grid, and thus interpolation is effectively done by selecting every other grid point, staggered every row or column. The model is forced by 18 time-dependent structure functions along the southeastern boundary and 1 time-dependent structure function in Rijeka Bay, with all values determined by data assimilation. The structure functions are each simply a grouping of velocity grid points to specify flow normal to the boundary and are grouped in such a way to avoid major depth changes within each block. Further discussion of how the boundary conditions are posed and how the structure function formulation is combined with a wave radiation term can be found in Reid and Bodine (1968) and Book et al. (2004). Along the southeastern boundary, structure function lengths vary between 4 and $12 \mathrm{~km}$ (see Figure 1 for locations and lengths of all 19 model structure functions). Locating a structure function in Rijeka Bay instead of Vela Vrata Strait was a practical choice as the model code required structure functions to be located at the boundary and moving the northeast model boundary further 
southwest would have cut off part of the Gulf of Trieste. Although not optimally placed, this structure function does act to determine the tidal energy flux through Vela Vrata Strait and provide realistic solutions for Kvarner Bay. Kvarnerić Bay (directly to the southeast of Rijeka Bay) and all straits and bays to the southeast are closed in the model; the model solutions for these areas and for Rijeka Bay are discarded.

The data-assimilation technique is a strong-constraint variational approach, where a cost function is formed to express data/model mismatch, and the derivatives of this cost function are calculated with respect to control variables. The controls are the 19 boundary conditions mentioned previously and both the forward model and an adjoint model are used to calculate the derivatives of the cost function with respect to these structure functions. A conjugate-gradient technique uses these derivatives to iterate to the solution that completely satisfies the discretized versions of Equations 2-4 (i.e., the strong constraint) and best fits the observations in a least-squares sense. Further details of this process can be found in Griffin and Thompson (1996) and Hallock et al. (2003). The model was run through 20 iterations using the complete Response Method tidal solution from all 15 bottom pressure time series and 14 vertically-averaged current time series (VR5 currents were excluded due to the uncertainty in direction, see Section 2.1). The cost function of data/model mismatch was evaluated over the model time period of February 1 through April 3,2003 with equal weight given to $1 \mathrm{~cm}$ and $1 \mathrm{~cm} / \mathrm{s}$ total $\mathrm{rms}$ over time and station. Optimization of these weights was not done. The assumption used is that these values approximately represent the relative accuracies of the pressure and velocity tidal time series and that all moorings are measuring these quantities with nearly the same accuracy.

\subsection{Tide model solutions}

The accuracy of the model solution can be fairly evaluated by considering the final reduction in the cost function value (i.e., model-data mismatch) that is achieved after all the conjugate-gradient iterations. It is not assured that a solution that matches the data well will be found because of the use of a strong constraint method, controls only in the boundary conditions, and use of less structure functions than the total number of data time-series. However, for this shallow-water model of the Adriatic, a solution was found that matches the data closely (Figure 3). The average rms errors were $0.81 \mathrm{~cm}$ for tidal elevations, $0.48 \mathrm{~cm} / \mathrm{s}$ for along-axis tidal currents, and $0.41 \mathrm{~cm} / \mathrm{s}$ for across-axis tidal currents. Book (2007) used the same rms metric to compare the solutions of Janeković and Kuzmić (2005) and the tidal solutions in Martin et al. (2006) to the same data and found higher error levels in these other solutions. The average error reductions in our solution from these models' rms values were $70 \%$ for elevation, $40 \%$ for along-axis currents, and $19 \%$ for across-axis currents. These results demonstrate that the vertically-averaged tides of the 

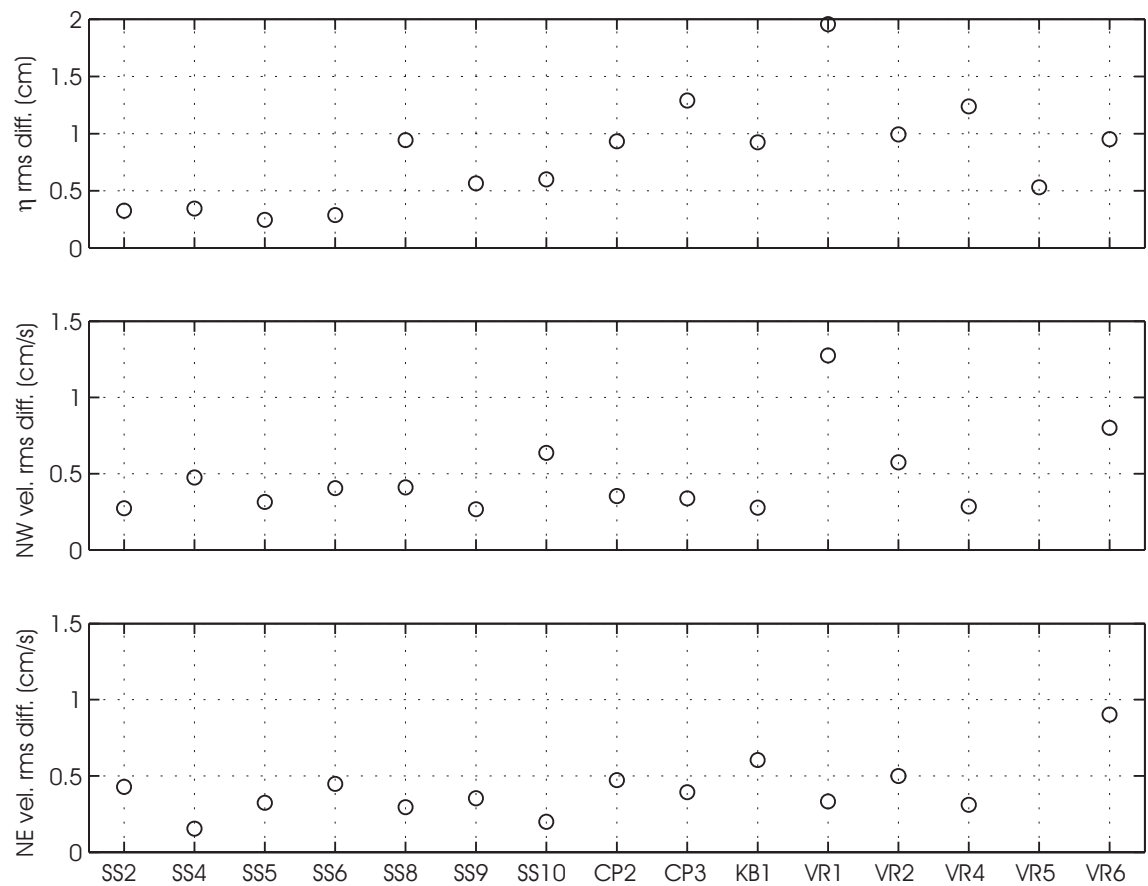

Figure 3. Rms errors between observed tidal data and model simulations. The top panel shows the rms errors from the tidal elevations. The middle panel shows rms errors from along-axis tidal velocities $\left(-45^{\circ} \mathrm{T}\right)$. The bottom panel shows rms errors from across-axis velocities $\left(45^{\circ} \mathrm{T}\right)$.

North Adriatic can be well reproduced from use of the linear shallow water equations if appropriate optimal boundary conditions are used.

To examine further the errors from our model results, a Response Method tidal analysis was done over the model time period for both the data and the model solutions interpolated to the data sites. This allows the errors in Figure 3 to be evaluated in terms of differences in tidal amplitudes, phases, and ellipse parameters and separation of error contributions according to tidal constituents. Figure 4 shows the results for $K_{1}, M_{2}$, and $S_{2}$. The highest errors occur at site VR1 for many metrics. This shallowest station could possibly be impacted by tides from the Venice Lagoon, located $16 \mathrm{~km}$ away, which our model does not accurately simulate (the Lagoon is closed in the model). At VR6, tidal parameter differences are similar to other sites (Figure 4 ), but a $5^{\circ}$ counterclockwise rotation of the model currents is enough to produce higher velocity rms differences (Figure 3) because tidal currents reach $10 \mathrm{~cm} / \mathrm{s}$ at that site.

The solutions on the full model grid were also analyzed using the Response Method using 58 days of model output ( 3 days beyond the model spin-up of 3 days and 1 day before the model spin-down of 0.7 days were discarded for 

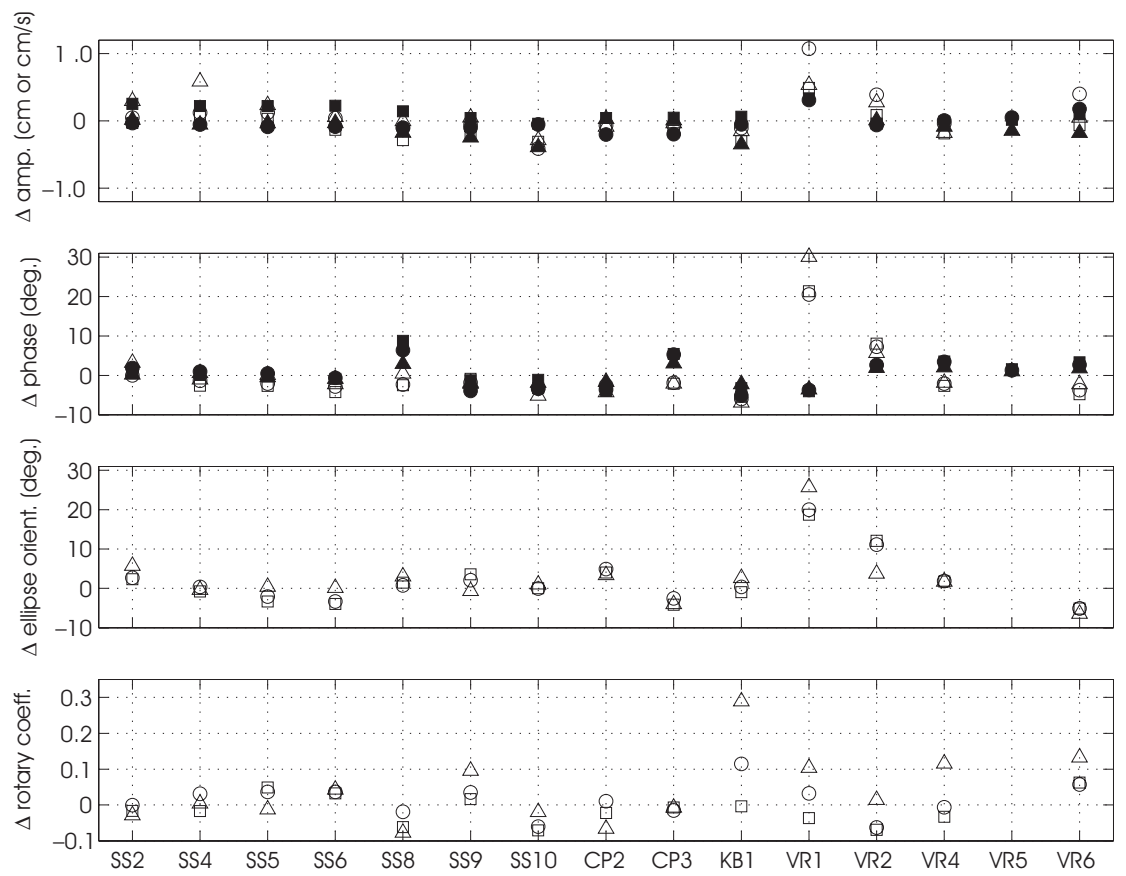

Figure 4. Differences (data - model) in tidal parameters for the $K_{1}(\triangle), M_{2}(\circ)$, and $S_{2}(\square)$ constituents. Amplitude and phase difference markers are filled for elevation differences and open for velocity differences. Positive differences indicate a model under prediction for amplitude, a model phase lead, clockwise model misalignment in velocity orientation, and a weaker clockwise rotational component in model velocity.

cautionary purposes). Figures $5-8$ show the resulting co-range and co-tidal maps and subsampled sets of the tidal velocity ellipses. These model fields fill out further details of the tidal structure and spatial trends that were already discussed in Section 2.2. In addition, some other features predicted by the model include weak tidal currents inside Kvarner Bay, and a zone of decreased ellipse eccentricity along the north coastline and also south of the Po River Delta. The zone along the north coastline arises from the Poincaré wave modes needed for Kelvin-wave reflections in a closed channel as previously discussed by Cavallini (1985), Mosetti (1986), and others.

Following Mosetti (1986) and Malačič et al. (2000), it is useful to examine the tidal ellipse structure in terms of the rotary coefficient (Equation 1). Figures 9 and 10 show the rotary coefficient values from the model for $M_{2}$ and $\mathrm{K}_{1}$ constituents, respectively. It is clear from Figure 9 that the $M_{2}$ tidal currents of the main basin of the North Adriatic closely approximate reversing-tide structure almost everywhere and that the extent of the Poincaré wave zones are quite confined near the coast in the northwest. A second Poincaré wave zone exists in a confined area to the south of the Po River Delta and it is possi- 


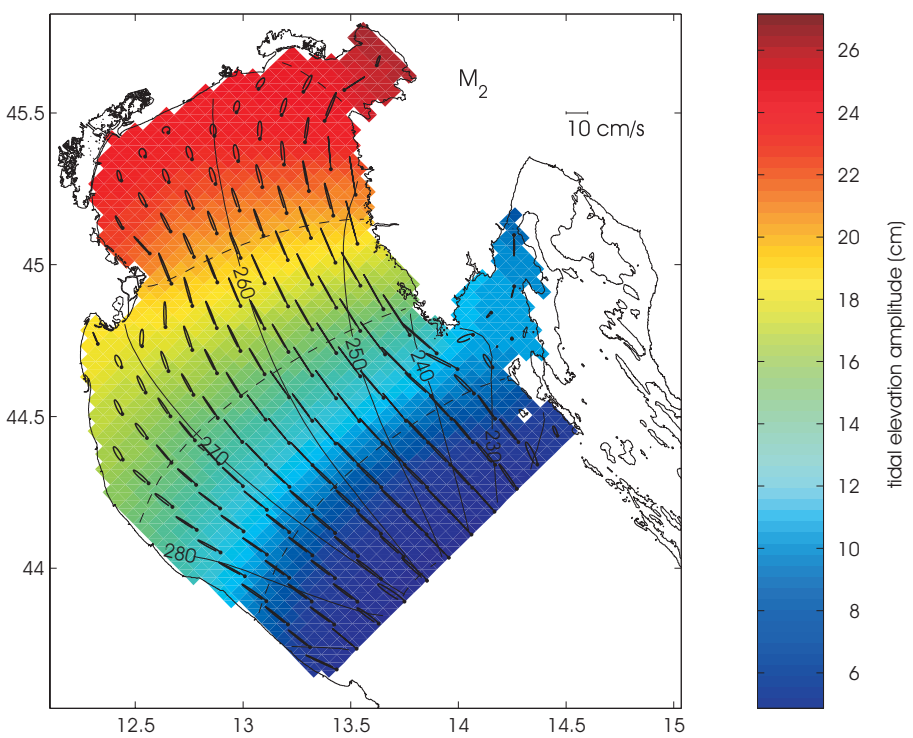

Figure 5. $M_{2}$ co-range and co-tidal map and tidal current ellipses from the data-assimilation model. Dashed lines are co-range lines (contour interval $5 \mathrm{~cm}$ ) and bold solid lines are co-phase lines with GMT phase lag labels in degrees. $M_{2}$ sea-surface elevation amplitudes are also indicated by the color field. Only every third ellipse in both the along- and across-axis directions of the Adriatic is shown for graphical clarity. The velocity scale for the ellipses is indicated in the upper right. Tidal currents rotate from the dot (time of the transit of the fictitious star) to the gap.

ble that Kelvin-wave reflections are also occurring from this coastal protrusion. Maps of $C_{R}$ are a good measure of Poincaré wave extension since such waves cannot exist as reversing tides $\left(C_{R}=0, u=0\right.$, and from the $u$ Poincaré wave solution, Kundu, 1990, one of the horizontal wave numbers must be imaginary and thus the solution reverts to a Kelvin-wave solution). The $K_{1} C_{R}$ map shows a similar structure to the $M_{2}$ map, but with an enhanced zone of slight clockwise rotation along the $50 \mathrm{~m}$ isobath ridgeline just northwest of the local peak in along-axis bathymetric slope magnitude. Further discussion of this interesting feature will be left to Section 4 . The $C_{R}$ maps from the model are in agreement with the observations (Figure 4 bottom panel) and show more strongly reversing currents than previous published maps and estimates.

The patches of alternating highs and lows of $C_{R}$ near the southeastern boundary that are especially evident in Figure 10 are spurious. They are caused by unconstrained null modes of the variational assimilation model where tidal energy can enter through one structure function and exit through another one without affecting the results at the observation locations. As substantiated by the $C_{R}$ maps, the null modes are confined to small-scale structures very near the boundary, as otherwise they would have projections to the nearby SS line and be determined by the data. 

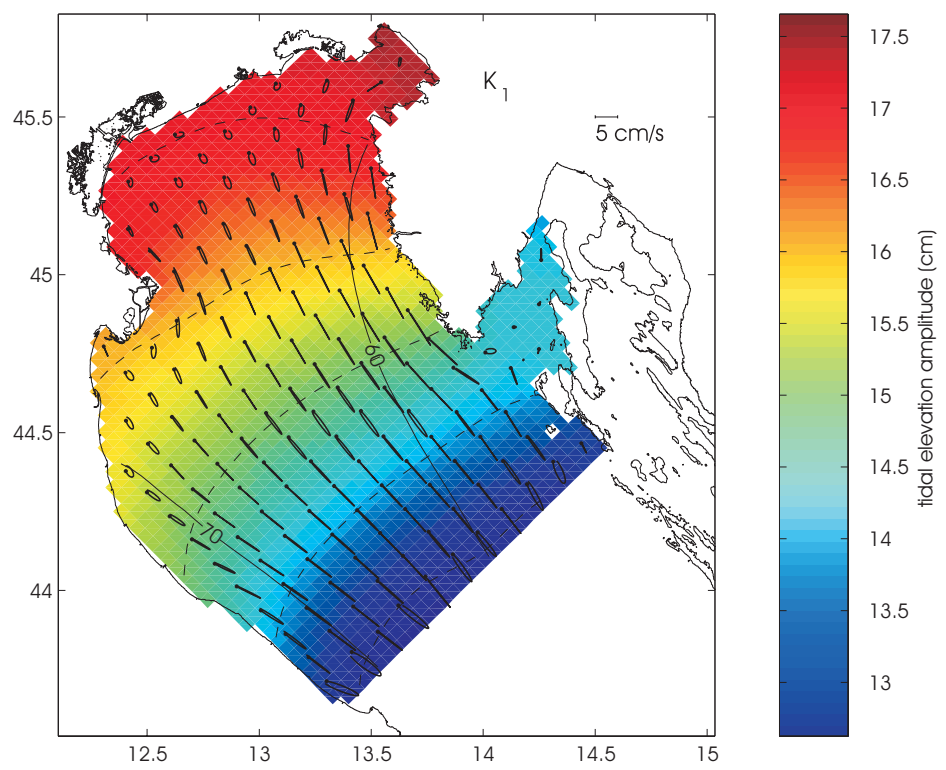

Figure 6. As in Figure 5 but for the $K_{1}$ tide (with co-range contour interval $1 \mathrm{~cm}$, and different velocity and color scales).
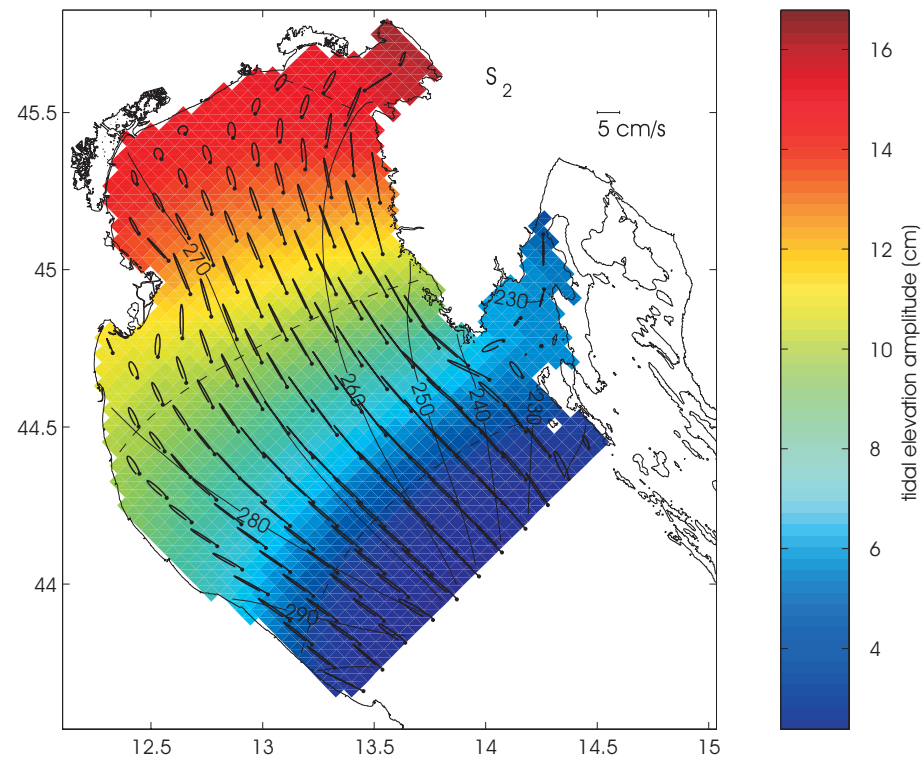

Figure 7. As in Figure 5 but for the $S_{2}$ tide (with co-range contour interval $5 \mathrm{~cm}$, a different color scale, and a velocity scale matching Figure 6 ). 

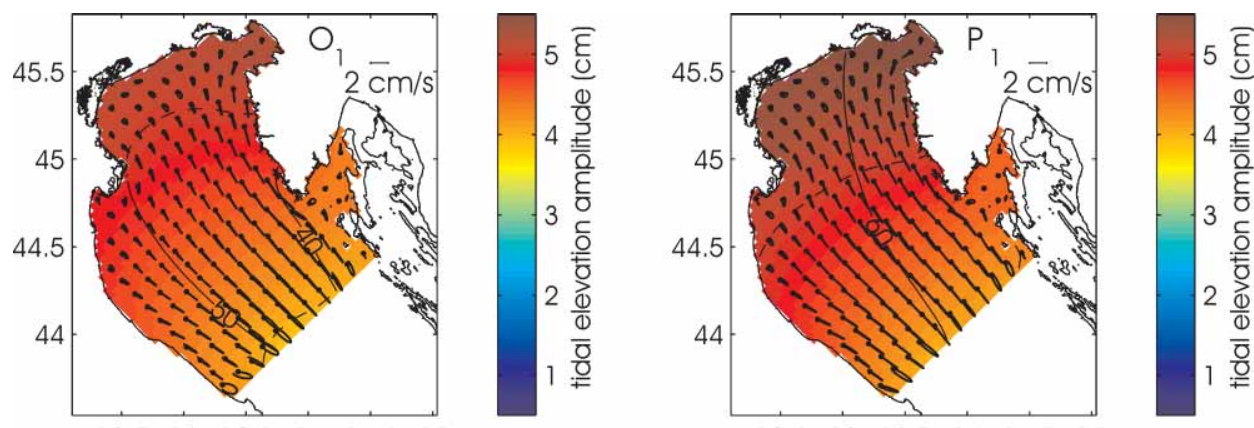

$\begin{array}{llllll}12.5 & 13 & 13.5 & 14 & 14.5 & 15\end{array}$

$\begin{array}{llllll}12.5 & 13 & 13.5 & 14 & 14.5 & 15\end{array}$
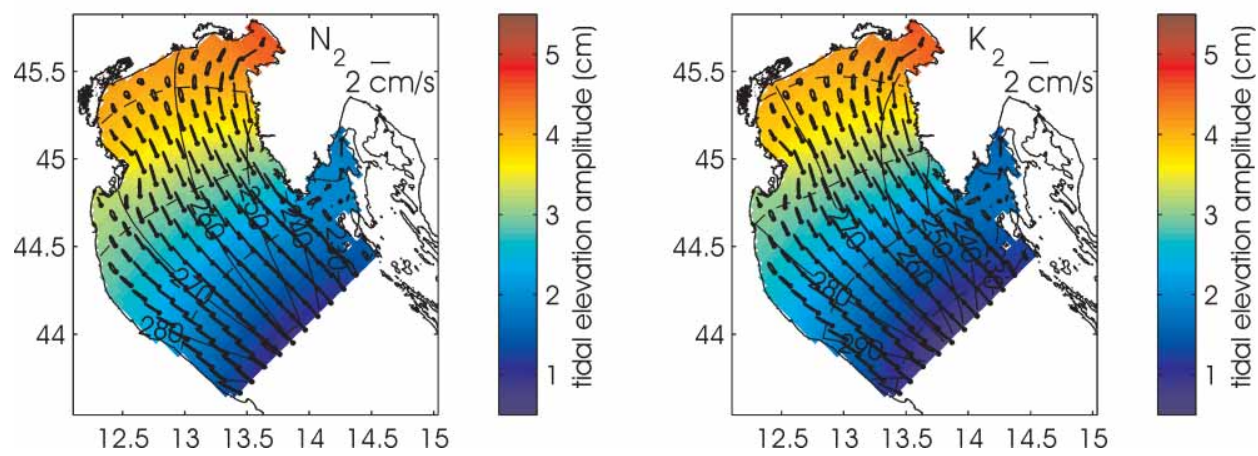

Figure 8. As in Figure 5 but for the $O_{1}, P_{1}, N_{2}$, and $K_{2}$ tides as labeled (with co-range contour interval $1 \mathrm{~cm}$ and consistent color and velocity scales for all panels).

\subsection{Tide model dissipation}

With the linear friction formulation of Equations 2-3, dissipation is directly proportional to kinetic energy, i.e., $(2 \lambda / h) K E$. The $Q$ factor of a basin for an individual tidal constituent is $2 \pi$ times the total energy stored in the basin divided by the dissipation over a tidal period, and is therefore, for our model with linear friction,

$$
Q=2 \pi \frac{\sum_{u, v} \overline{K E}+\sum_{\eta} \overline{P E}}{2 \lambda \frac{2 \pi}{\omega} \sum_{u, v} \frac{\overline{K E}}{h}},
$$

where $\omega$ is the tidal constituent angular frequency, $K E$ and $P E$ are the kinetic and potential energies at the grid points, and the overbar indicates averaging over a tidal period. If there is equipartition of kinetic and potential energy, 
this expression can be approximated as $Q \approx \tilde{h} \omega / \lambda$ and the $Q$ factor of the basin in the model is directly determined by the value of $\lambda$, the average depth of the basin $(\tilde{h})$, and the tidal constituent frequency.

We directly calculated $Q$ from Equation 5 for the $M_{2}$ and $K_{1}$ tides. For $M_{2}$ tides, $Q=14.0$ and the $e$-folding time for energy dissipation is 2.2 tidal cycles. For $M_{2}$, energy is not equally partitioned between $K E$ and $P E$ in the basin because the PE stored over a tidal cycle exceeds the $K E$ by $50 \%$. For $K_{1}$ tides, $Q$ $=22.4$ and the $e$-folding time for energy dissipation is 3.6 tidal cycles. For $K_{1}$, the $P E$ stored over a tidal cycle is 6.1 times the $K E$ and accordingly these lower frequency waves are damped more slowly than the higher frequency $M_{2}$ waves.

The 23.93 hour $K_{1}$ tidal period is close to the lowest mode of natural resonance of the Adriatic, the seiche period, estimated from past research at 21-22 hours (Cushman-Roisin et al., 2001). Therefore it is interesting to compare our $K_{1}$ energy dissipation $e$-folding time to energy dissipation $e$-folding times estimated by Cerovečki et al. (1997) from measurements of Adriatic seiches. From a seiche decay event relatively free of additional wind influences, they found a decay time of 3.2 days, but this decay combines both frictional dissipation and radiation loss through the Strait of Otranto. Using a linear frictional parameter over the entire Adriatic of $4.5 \cdot 10^{-4} \mathrm{~m} / \mathrm{s}$, they matched the net decay time by radiating $32 \%$ of the energy per period, but with a frictional parame-

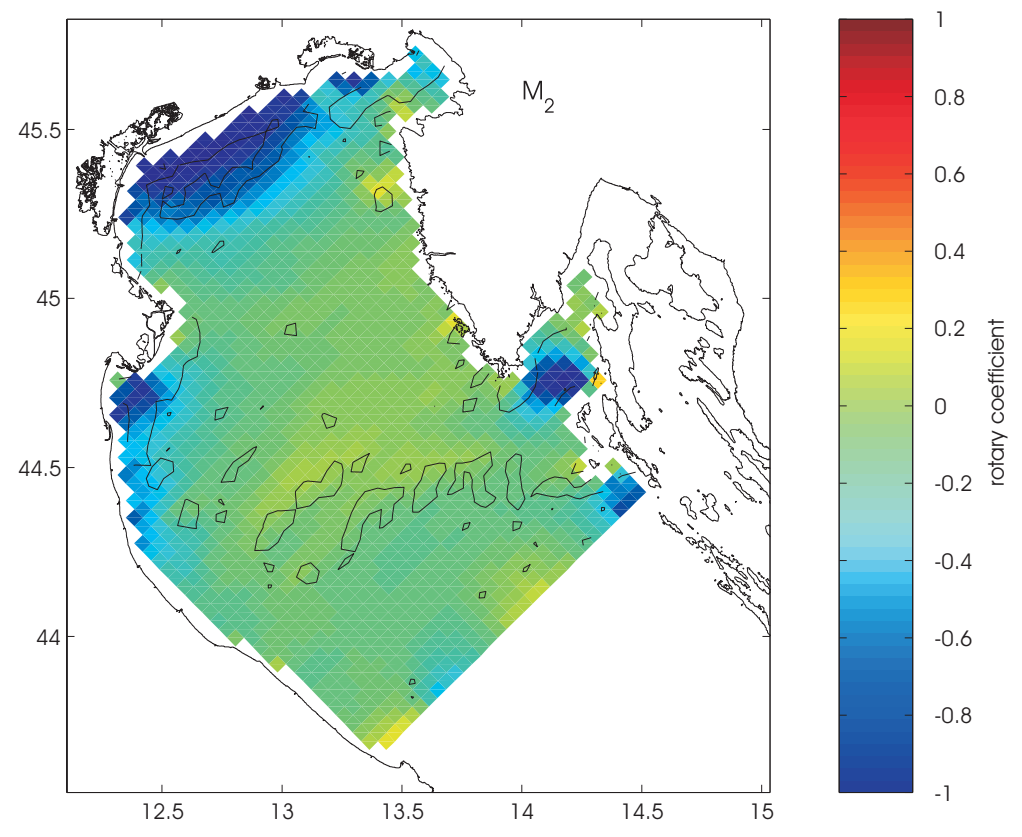

Figure 9. Rotary coefficient, $C_{R}$, calculated from the modeled $M_{2}$ tidal currents. The $-63 \mathrm{~m} / 100 \mathrm{~km}$ along-axis bathymetry slope contours are shown in black for reference. 
ter of $6.4 \cdot 10^{-4} \mathrm{~m} / \mathrm{s}$ only $9 \%$ radiation was needed. These cases yield energy dissipation $e$-folding times of 4.73 and 3.55 days similar to our $K_{1}$ energy dissipation time of 3.6 days. Similar $Q$ factors for $K_{1}$ tides and the fundamental Adriatic seiche imply similar energy distribution despite different forcing mechanisms, and illustrate a close connection between the $K_{1}$ response and the natural resonance of the basin.

In the model, the value of $\lambda$ was selected by making a series of preliminary runs and determining the friction coefficient value that yielded the lowest final cost function minimum. Figure 11 shows the cost function variation for the different values of $\lambda$ that were tested. Note that each of these cost function values is the final minimum after 20 iterations of the conjugate-gradient technique. The cost function values should be compared to the values for a modeled Adriatic sea at rest which are 921.6 and 169.6 for the tidal elevations and tidal currents, respectively. Thus, changing $\lambda$ in this subset of friction coefficient range does not lead to large differences in the final model solution. E.g., the maximum increases in average elevation and average velocity rms errors due to friction coefficient changes within the range shown are $23 \%$ and $12 \%$, respectively. However, in part because of this fact, the average tidal dissipation is sensitive to the value of $\lambda$ (Figure 11, right panel). The cost function tries to prevent the tidal velocities from departing very far from the observations after optimization of the boundary conditions and therefore increases in $\lambda$ are likely partially compensated by increases in net energy flux at the boundaries. Thus, the simulated $K E$ of the basin remains relatively constant,
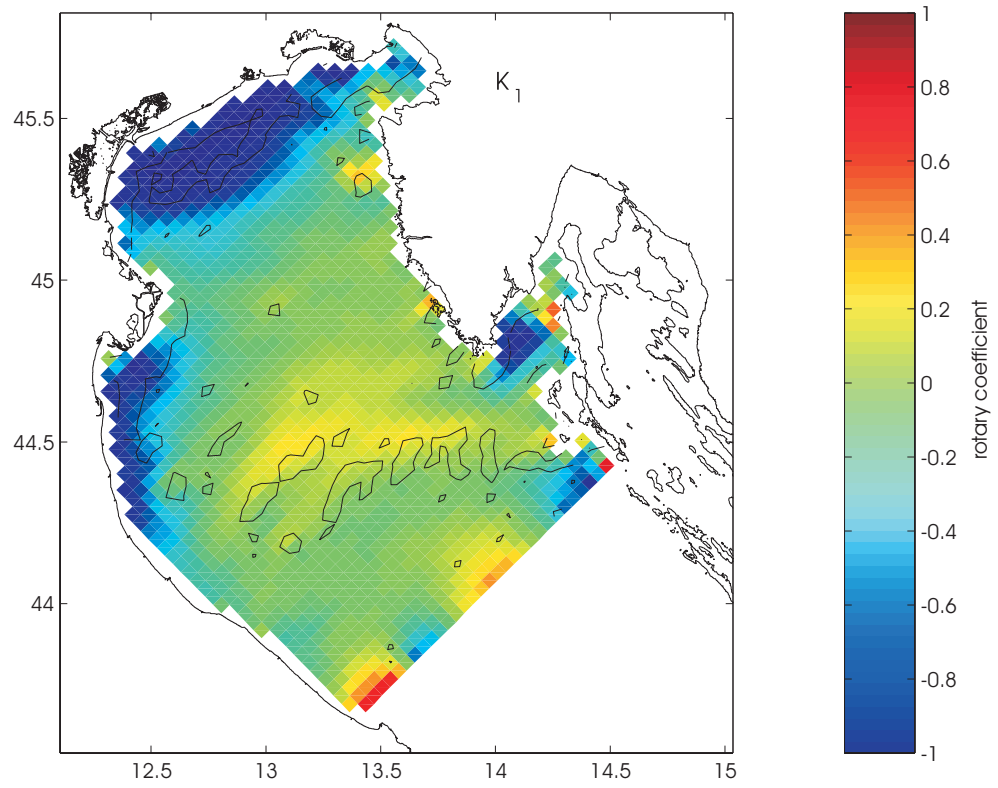

Figure 10. As in Figure 9 but for $K_{1}$ tides. 
but dissipation increases approximately in proportion to increases in $\lambda$. This is opposite to the behavior found by Lefèvre et al. (2000) for a model without data assimilation and fixed boundary forcing, where their velocities could freely adapt to changes in friction coefficient and act to keep the model dissipation relatively constant and in balance with the net boundary energy flux as frictional forces were increased. The average dissipation for our model domain from the run that produced the lowest cost function value was $49 \mathrm{MW}$, but this value is not tightly constrained within our method of determining it.

However, the dissipation of the model at the mooring sites can be checked against data estimates because Book et al. (2009) used the observed vertical structure of the tidal velocities with bottom Ekman layer theory to deduce bottom friction parameters, including bottom shear stress. Therefore, the dot product of observed vertically-averaged tidal velocities with these bottom shear stress estimates is the dissipation and diffusion of kinetic energy per meter squared and can be directly compared to the model dissipation per me-
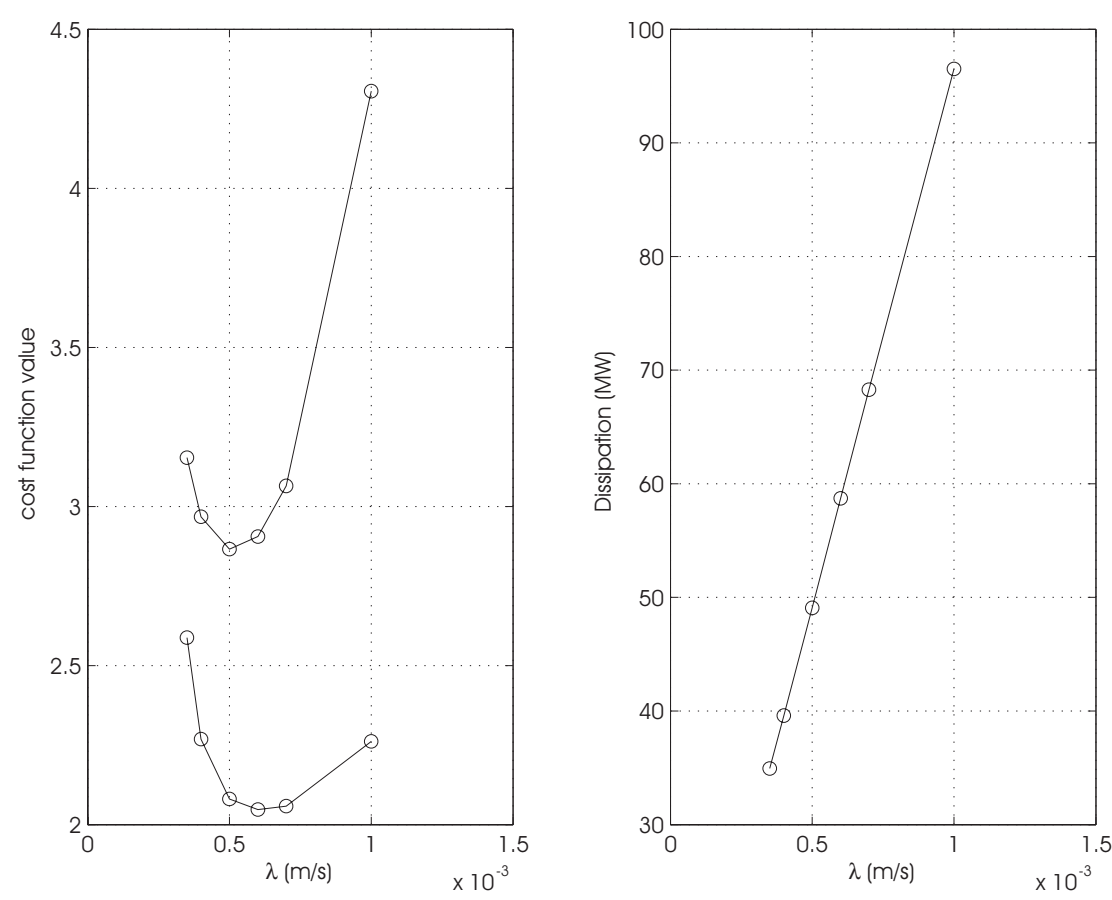

Figure 11. The cost function contributions (left panel) from model-data mismatches of tidal elevations (upper curve) and currents (lower curve) in the variational data-assimilation model runs for different friction parameters, and the resulting average dissipation for the model domain (right panel) estimated from the model solutions. The total cost function is the sum of the two curves in the left panel. Based on these results, the run that used $\lambda=5 \cdot 10^{-4} \mathrm{~m} / \mathrm{s}$ was chosen for the final model solution. 
ter squared, $\rho \lambda\left(u^{2}+v^{2}\right)$, at the mooring sites (Figure 12). In all but one comparison, the model dissipation exceeds the dissipation determined from the theoretical fit to the observed vertical tide structure. The average model dissipation over the mooring sites for the $K_{1}, M_{2}$, and $S_{2}$ tides is 2.3, 2.1, and 2.1 times the average dissipation from the observational estimates. If these results at the mooring sites can be extended basin-wide, then $23 \mathrm{MW}$ would be a better estimate of the true average dissipation of the North Adriatic basin rather than $49 \mathrm{MW}$. However, lowering $\lambda$ in the model does not yield better results (Figure 11), likely due to the fact that a linear friction formulation does not correctly account for the frictional tide orientation and phase shifts near the bottom which lead to bottom shear stresses that are not aligned or phased with the vertically-averaged tide (Book et al., 2009).

We have neglected the possible influence of internal tides in the model solutions by ignoring all terms involving density stratification in the equations and removing almost all of their potential influence on the assimilated data by vertically averaging tidal currents measured over the portion of the year with low levels of stratification (Figure 2, Jeffries and Lee, 2007). Actual generation of internal tides in the North Adriatic would cause an additional sink of en-

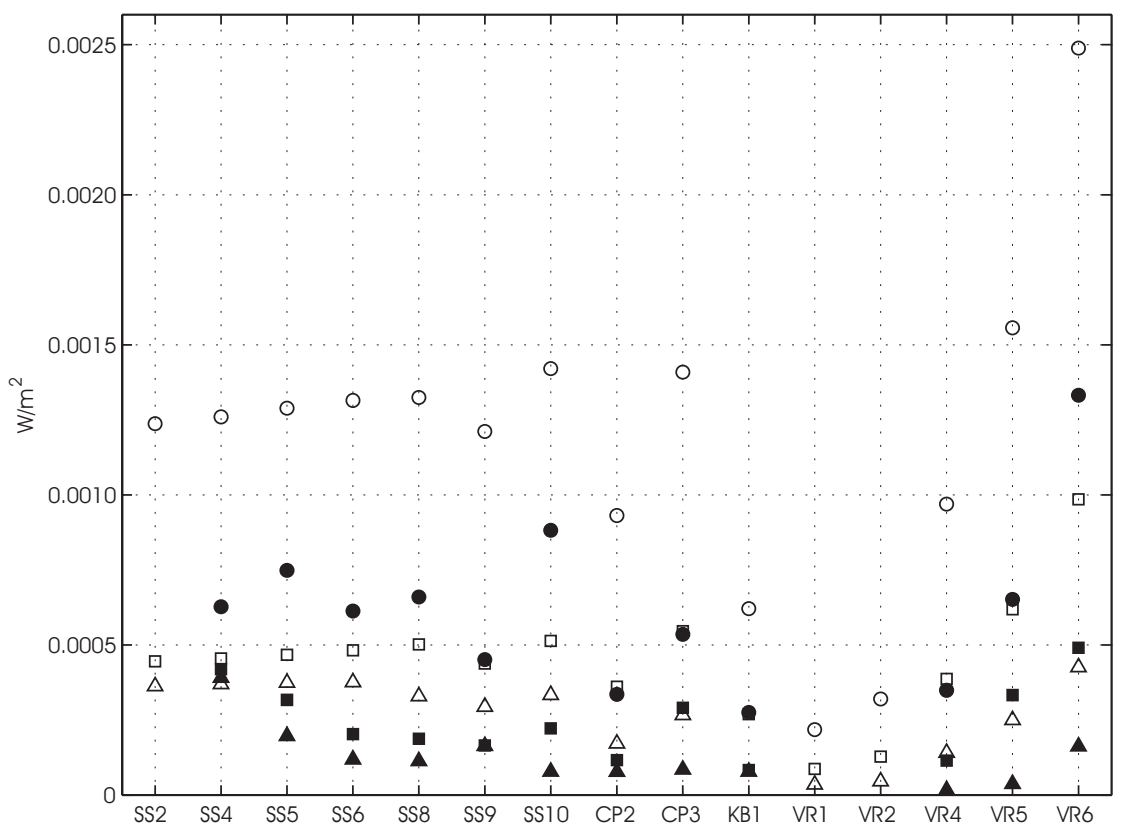

Figure 12. Dissipation calculated from the model (open symbols) and from an Ekman bottom boundary layer theoretical fit (filled symbols) to the observed vertical structure of the tides (Book et al., 2009) at the mooring sites for the $K_{1}(\triangle), M_{2}(\circ)$, and $S_{2}(\square)$ constituents. Sites SS2, VR1, and VR2, were all too shallow for the theoretical fitting methodology of Book et al. (2009) and therefore no filled symbol estimates could be calculated for these sites. 
ergy from the vertically averaged tides, and the linear friction parameter of the model could optimize to a higher value to compensate for this effect which is missing from the model. This could cause the dissipation estimated using the friction parameter to exceed the true dissipation caused by bottom friction. However, a typical ratio of the bathymetric slope to the slope of the semidiurnal internal wave characteristic is estimated to be less than 0.1 and therefore significant generation of internal tides (Table 1, Craig, 1987) in the North Adriatic is unlikely for the months of our study. This agrees with the general lack of baroclinic structure (with a few exceptions) observed in tidal currents at the mooring sites (Book et al., 2009), and therefore it is improbable that internal tide generation could account for the dissipation estimate discrepancies discussed here.

Our optimized linear frictional parameter value of $\lambda=5 \cdot 10^{-4} \mathrm{~m} / \mathrm{s}$ is within the range independently estimated by Cerovečki et al. (1997) using Adriatic seiche decay estimates. It is lower than the values $\left(11-12 \cdot 10^{-4} \mathrm{~m} / \mathrm{s}\right)$ found by Orlić et al. (1986) for a strong wind case with higher velocities than tidal flows, but also lower than the values $\left(6-15 \cdot 10^{-4} \mathrm{~m} / \mathrm{s}\right)$ found by Orlić (1987) for inertial oscillations with velocities similar to those of the tidal flows. However, note that optimization for currents alone in our study favors higher values of $\lambda$

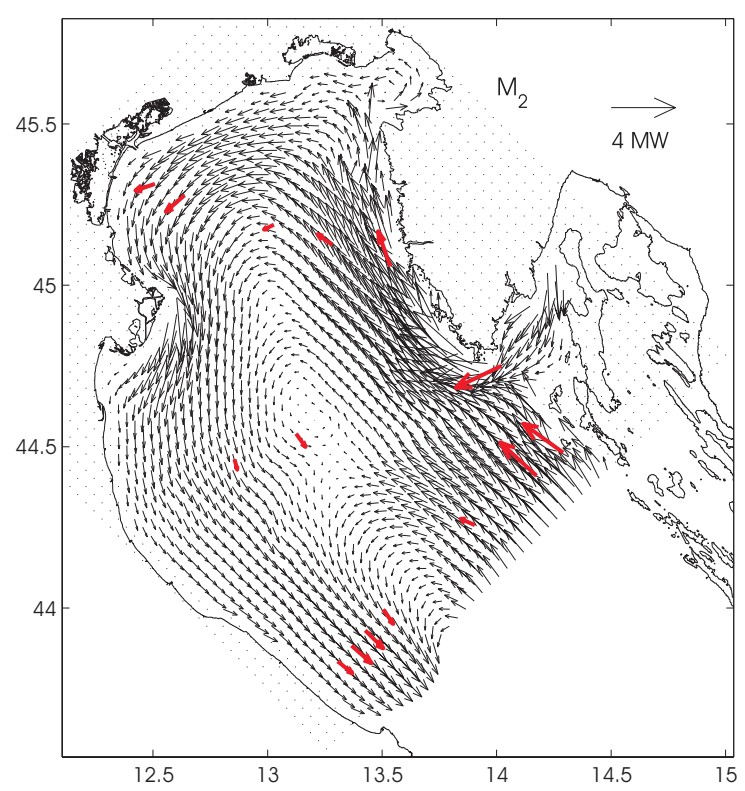

Figure 13. Average $M_{2}$ energy flux over a tidal cycle calculated from the observations (red arrows) and model solutions (black arrows). The energy flux scale is given in the upper right. For purposes of model/data comparison, the energy fluxes per meter calculated from the tidal observations were multiplied by $4 \mathrm{~km}$, the length of the model grid spacing, to convert them into total energy fluxes. 
(Figure 11) than optimization for both currents and elevations and this might be a factor in comparisons with these other estimates based on current measurements. Together with the previous studies, our results suggest that $5 \cdot 10^{-4}$ $\mathrm{m} / \mathrm{s}$ is a good estimate for an Adriatic linear friction parameter in tide-only simulations, it likely should be increased if additional processes are simulated, but dissipation estimated from its use could be too high due to the deficiencies of the linear friction approximation (Book et al., 2009).

\section{Discussion}

Tidal energy flux is a useful quantity to examine the reversing tide structure of the North Adriatic. The energy flux per unit length of the vertically-averaged tide over a tidal period is

$$
\vec{F}=\rho g h \overline{(\eta u \hat{i}+\eta v \hat{j})}=\frac{1}{2} \rho g h \eta_{a}\left[u_{a} \cos \left(\eta_{p}-u_{p}\right) \hat{i}+v_{a} \cos \left(\eta_{p}-v_{p}\right) \hat{j}\right]
$$

where the $a$ and $p$ subscripts denote the amplitude and phases, and $\hat{i}$ and $\hat{j}$ are unit vectors in the across-axis $(x)$ and along-axis $(y)$ directions. As we measured velocities and elevations simultaneously at each mooring location, $\vec{F}$ can be directly calculated from observed quantities as well as from the model fields. Figures 13 and 14 show the results.

The $M_{2}$ flux fields show the structure of an incident and a reflected Kelvin wave, and the model energy fluxes agree well in magnitude and direction with the observations. The asymmetry between the two waves is consistent with the concept of tidal dissipation localized at the head of the "channel" as shown by Hendershott and Speranza (1971). There is a small departure from Kelvin-wave structure in the overlap zone between the wave modes where weak energy fluxes are directed across the basin, towards the southwest.

The general strong agreement with Kelvin-wave structures in the $M_{2}$ map does not preclude the possible existence of a TRW component, because TRWs for purely reversing tides have zero energy flux in both directions averaged over a tidal period. The restriction $u \equiv 0$ for purely reversing tides forces all across-axis energy fluxes to be identically zero, and $\eta$ and $v$ are out of phase for TRWs so the along-axis energy flux over a tidal period is also zero. Because of the zero energy flux of such theoretical TRW modes, small departures (e.g., $u \neq 0$ ) from reversing tides could potentially have large impacts on the wave energy flux without greatly affecting the momentum or mass balances of the waves.

Note that, somewhat surprisingly, the strongest observed energy flux was at site KB1 inside Kvarner Bay. This energy flux was $0.78 \mathrm{~kW} / \mathrm{m}$ in magnitude and substantiates the model simulations of large tidal fluxes entering the North Adriatic from Vela Vrata Strait by way of Kvarner Bay. Although the tidal currents in the bay are small, the phase relationship between the cur- 
rents and the tidal elevations produce a strong flux out of the bay. In the model, this flux appears to play a role in the tidal enhancement observed along the Istrian coast.

The $K_{1}$ fields (Figure 14) show a different structure. One of the clearest differences in $K_{1}$ energy fluxes from $M_{2}$ fluxes is the band of northeastward directed energy just to the south and east of mooring CP3, near the $50 \mathrm{~m}$ isobath. As seen on Figure 10, this zone is where the rotary coefficients of the tides become slightly positive and is along a line just north of some of the steepest slopes in the model domain. Northwest of the ridge, the slopes are less steep and the energy flux structure resembles a Kelvin wave just as for $M_{2}$. Against the southwest coast the $K_{1}$ energy flux structure resembles that of a down-slope Kelvin wave closely trapped to the coast (contrast the observed energy fluxes for $K_{1}$ and $M_{2}$ at sites SS2-6). As previously discussed for Figure 10 , there are spurious solutions in the null space near the southeastern model boundary.

Further support for the existence of TRWs can be found in other results. The departure from equipartition of energy for both $M_{2}$ and $K_{1}$ (Section 3.2) is suggestive, especially the large ratio for $K_{1}$ tides, as individual Kelvin waves have equipartition of energy but TRWs do not. The difference in the solutions for $M_{2}$ and $K_{1}$ near the boundary and the strange $K_{1}$ null space structure might also indicate a difference in wave types. The admittance used in the

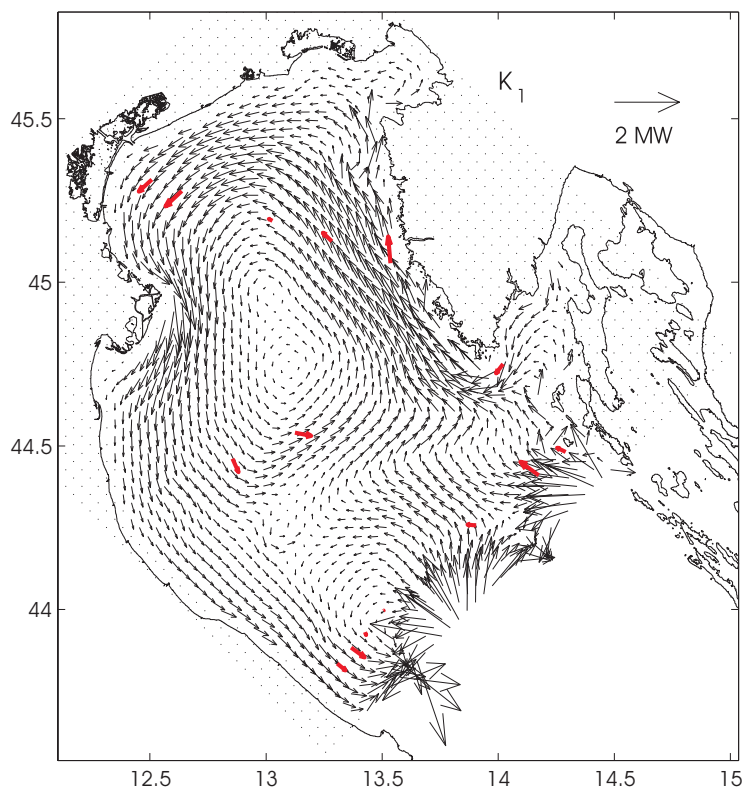

Figure 14. As in Figure 13 but for $K_{1}$ tides with a different energy flux scale. 
model boundary conditions (Book et al., 2004) is $\sqrt{g / h}$ and is exactly correct for Kelvin waves but incorrect for TRWs. Therefore, the relatively clean structure near the boundary for $M_{2}$ as opposed to spurious structures near the boundary for $K_{1}$ could indicate that the structure functions for $K_{1}$ are forced to compensate for the less than optimally posed (for TRWs) boundary conditions by exciting null modes. Nevertheless, the model does overcome these issues and away from the boundary the correct wave structures are excited as evidenced by the close model-data agreement. From the $K_{1}$ energy fluxes it is clear that $K_{1}$ tidal solutions in the North Adriatic do not closely match either incident and reflected Kelvin wave structures only, or TRW structures only.

\section{Conclusions}

Fifteen moorings deployed in the North Adriatic basin for more than six months provided open-sea observations of tidal velocity and elevation from which energy flux and dissipation were calculated and a tidal model was constrained. The observations themselves show nearly reversing tidal currents at all locations except in Kvarner Bay and near the northwest corner of the sea, and increasing tidal current strength near Istria. Tidal elevation amplitudes all increase towards the northwest, but with semidiurnal constituents increasing by more than $200 \%$ and diurnal constituents increasing by less than $50 \%$. Tidal elevation phases increase counterclockwise around the basin from the northeast coast to the southwest coast, but with semidiurnal phase increase three times that of the diurnal phase.

The observational data are used in an optimal determination of boundary conditions for a linear strong-constraint variational data assimilation model with a tuned friction parameter. Average rms model-data differences were $0.81 \mathrm{~cm}$ for tidal elevations, $0.48 \mathrm{~cm} / \mathrm{s}$ for along-axis tidal currents, and 0.41 $\mathrm{cm} / \mathrm{s}$ for across-axis tidal currents. The highest errors occurred near Venice, possibly because the Venice Lagoon is closed in the model. Rotary coefficients from the model extend the observational finding of nearly reversing tidal structure to much of the basin and the Poincaré wave reflection zone is shown to be closely trapped to the coast. Calculation of $Q$ factors from the model produce $e$-folding times for energy dissipation of 2.2 tidal cycles for $M_{2}$ and 3.6 tidal cycles for $K_{1}$. The total average dissipation in the model was $49 \mathrm{MW}$. However, this result is very sensitive to the value of the linear friction coefficient and comparisons between model dissipation at the mooring sites and dissipation estimated from the data (Book et al., 2009) show that the model's dissipation could be more than two times too large. The model's total average potential energy is 1.5 times the total average kinetic energy for $M_{2}$ and 6.1 times for $K_{1}$, indicating departures from Kelvin-wave structure for which energy is equally partitioned. 
$M_{2}$ energy fluxes support the previous published concept (Taylor, 1921; Hendershott and Speranza, 1971; Mosetti, 1986) of incident and reflected Kelvin waves, with some modification. In the $M_{2}$ fluxes there is a modeled asymmetry in the incident and reflected waves likely due to friction, and some southwestward turning of energy fluxes in the overlap zone between the wave modes. Additionally the highest energy flux of all the moorings was observed at the north entrance of Kvarner Bay, suggesting that this bay and fluxes through Vela Vrata Strait are significant in the North Adriatic energy balance. $K_{1}$ energy fluxes show evidence for both TRW modes (indirectly) and Kelvin-wave modes existing together. The most significant departure from Kelvin wave structure is a modeled northeastward cross-basin flux near the 50 $\mathrm{m}$ isobath where the bathymetric slope is particularly steep. Departures from Kelvin-wave structure are also seen south of this ridge, but Kelvin-wave-like structures persist all along the southwest coast and to the north of the ridge where the bathymetry is less steep.

Acknowledgments - We thank Mark Hulbert and Ray Burge of NRL, the technical mooring team of NURC, and all those aboard the RV Alliance during the adria23 cruises for their work in the successful deployment and recovery of all the JRP moorings. We thank Richard Signell for sharing the NURC mooring data. We thank Dave Hebert, Ivica Janeković, Mike Kuzmić, Paul Martin, Tom Rossby, Malcolm Spaulding, Bud Vincent, Hans Ngodock, Scott Pope, and two anonymous reviewers for their comments on portions of this work. The work of J. W. Book and H. Perkins was supported by the Office of Naval Research as part of the research program "Adriatic Circulation Experiment" and "Environmental Optimization of Sea-Bed Energy Harvesting for Navy Devices" under Program Element Number $0602435 \mathrm{~N}$. Additional support for the work of J. W. Book was provided by the NRL Advanced Graduate Research Program. This is NRL contribution NRL/JA/7330-09-9277. We dedicate this work to the memory of Pavel Pistek who was instrumental in the development and application of the variational data-assimilation modeling program at NRL.

\section{References}

Book, J.W. (2007): Northern Adriatic circulation and tides. Ph.D. thesis, Graduate School of Oceanography, University of Rhode Island, Narragansett.

Book, J.W., Martin, P.J., Janeković, I., Kuzmić, M. and Wimbush, M. (2009): Vertical structure of bottom Ekman tidal flows: Observations, theory, and modeling from the northern Adriatic, $J$. Geophys. Res., 114(C01S06), DOI:10.1029/2008JC004736.

Book, J.W., Perkins, H., Signell, R.P. and Wimbush, M. (2007a): The Adriatic Circulation Experiment winter 2002/2003 mooring data report: A case study in ADCP data processing, Memorandum Report NRL/MR/7330-07-8999, U.S. Naval Research Laboratory, Stennis Space Center, MS 39529-5004.

Book, J.W., Pistek, P., Perkins, H., Thompson, K.R., Teague, W. J., Jacobs, G.A., Suk, M.-S., Chang, K.-I., Lee, J.-C. and Choi, B.H. (2004): Data assimilation modeling of the barotropic tides in the Korea/Tsushima Strait, J. Oceanogr., 60, 977-993.

Book, J.W., Signell, R.P. and Perkins, H. (2007b): Measurements of storm and nonstorm circulation in the northern Adriatic: October 2002 through April 2003, J. Geophys. Res., 112(C11S92), DOI:10.1029/2006JC003556. 
Cavaleri, L. (2000): The oceanographic tower Acqua Alta - activity and prediction of sea states at Venice, Coast. Eng., 39, 29-70.

Cavallini, F. (1985): A three-dimensional numerical model of tidal circulation in the northern Adriatic Sea, B. Oceanol. Teor. Appl., 3, 205-218.

Cerovečki, I., Orlić, M. and Hendershott, M.C. (1997): Adriatic seiche decay and energy loss to the Mediterranean, Deep-Sea Res. I, 44(12), 2007-2029.

Chavanne, C., Janeković, I., Flament, P. Poulain, P.-M., Kuzmić, M. and Gurgel, K.-W. (2007): Tidal currents in the northwest Adriatic: High-frequency radio observations and numerical model predictions, J. Geophys. Res., 112(C03S21), DOI:10.1029/2006JC003523.

Craig, P.D. (1987): Solutions for internal tidal generation over coastal topography, J. Mar. Res., 45, 83-105.

Cushman-Roisin, B., Malačič, V. and Gačić, M. (2001): Chapter 7: Tides, seiches and low-frequency oscillations, in B. Cushman-Roisin, M. Gačić, P.-M. Poulain, and A. Artegiani (Eds.), Physical Oceanography of the Adriatic Sea: Past, Present and Future, Kluwer Academic Publishers, 217-240 pp.

Cushman-Roisin, B. and Naimie, C.E. (2002): A 3D finite-element model of the Adriatic tides, $J$. Mar. Res., 37, 279-297.

Foreman, M.G.G. (1977): Manual for tidal heights analysis and prediction, Pacific Marine Science Report 77-10, Institute of Ocean Sciences, Patricia Bay, Sidney, BC, Canada.

Foreman, M.G.G. (1978): Manual for tidal currents analysis and prediction, Pacific Marine Science Report 78-6, Institute of Ocean Sciences, Patricia Bay, Sidney, BC, Canada.

Gonella, J. (1972): A rotary-component method for analysing meteorological and oceanographic vector time series, Deep-Sea Res., 19, 833-846.

Griffin, D.A. and Thompson, K.R. (1996): The adjoint method of data assimilation used operationally for shelf circulation, J. Geophys. Res., 101(C2), 3457-3477.

Hallock, Z.R., Pistek, P., Book, J.W., Miller, J.L., Shay, L.K. and Perkins, H.T. (2003): A description of tides near the Chesapeake Bay entrance using in situ data with an adjoint model, $J$. Geophys. Res., 108(C3), DOI:10.1029/2001JC000820.

Hendershott, M.C. and Speranza, A. (1971): Co-oscillating tides in long, narrow bays; The Taylor problem revisited, Deep-Sea Res., 18, 959-980.

Hicks, S.D. (2000): Tide and current glossary, Special Publication 228, U.S. Department of Commerce, National Oceanic and Atmospheric Administration, Silver Spring, MD.

Janeković, I., Bobanović, J. and Kuzmić, M. (2003): The Adriatic Sea $\mathrm{M}_{2}$ and $\mathrm{K}_{1}$ tides by $3 \mathrm{D}$ model and data assimilation, Estuar. Coast. Shelf S., 57, 873-885.

Janeković, I. and Kuzmić, M. (2005): Numerical simulation of the Adriatic Sea principal tidal constituents, Ann. Geophys., 23, 3207-3218.

Jeffries, M.A. and Lee, C.M. (2007): A climatology of the northern Adriatic Sea's response to bora and river forcing, J. Geophys. Res., 112(C03S02), DOI:10.1029/2006JC003664.

Kundu, P.K. (1990): Fluid Mechanics, Academic Press, Inc., San Diego, 638 pp.

Lee, C.M., Askari, F., Book, J., Carniel, S., Cushman-Roisin, B., Dorman, C., Doyle, J., Flament, P., Harris, C.K., Jones, B.H., Kuzmić, M., Martin, P., Ogston, A., Orlić, M., Perkins, H., Poulain, P.-M., Pullen, J., Russo, A., Sherwood, C., Signell, R. P. and Detweiler, D.T. (2005): Northern Adriatic response to a wintertime Bora wind event, EOS Transactions, 86(16), 19 April.

Lefèvre, F., Provost, C.L. and Lyard, F.H. (2000): How can we improve a global ocean tide model at a regional scale? A test on the Yellow Sea and East China Sea, J. Geophys. Res., 105(C4), 8707-8725.

Malačič, V., Viezzoli, D. and Cushman-Roisin, B. (2000): Tidal dynamics in the northern Adriatic Sea, J. Geophys. Res., 105(C11), 26265-26280. 
Martin, P.J., Book, J.W. and Doyle, J.D. (2006): Simulation of the northern Adriatic circulation during winter 2003, J. Geophys. Res., 111(C03S12), DOI:10.1029/2006JC003511. (printed 112 (C3), 2007).

Mihanović, H., Orlić, M. and Pasarić, Z. (2006): Diurnal internal tides detected in the Adriatic, Ann. Geophys., 24, 2773-2780.

Mihanović, H., Orlić, M. and Pasarić, Z. (2009): Diurnal thermocline oscillations driven by tidal flow around an island in the Middle Adriatic, J. Marine Syst., 78, S157-S168, DOI:10.1016/j. jmarsys.2009.01.021.

Mosetti, R. (1986): Determination of the current structure of the $\mathrm{M}_{2}$ tidal component in the northern Adriatic by applying the rotary analysis to the Taylor problem, B. Oceanol. Teor. Appl., 4, $165-172$.

Munk, W. H. and Cartwright, D. E. (1966): Tidal spectroscopy and prediction, Philosophical Transactions of the Royal Society of London, 259, 533-581.

Orlić, M. (1987): Oscillations of the inertial period on the Adriatic Sea shelf, Cont. Shelf Res., 7(6), $577-598$.

Orlić, M., Kuzmić, M. and Vučak, Z. (1986): Wind-curl currents in the northern Adriatic and formulation of bottom friction, Oceanol. Acta, 9, 425-431.

Perkins, H. T., de Strobel, F. and Gualdesi, L. (2000): The Barney Sentinel Trawl-resistant ADCP bottom mount: design, testing, and application, IEEE J. Oceanic Eng., 25, 430-436.

Polli, S. (1959): La Propagazione della Maree nell' Adriatico, Atti del IX Convergo dell' Associazione Geofisica Italiana, Rome.

Reid, R.O. and Bodine, B.R. (1968): Numerical model for storm surges in Galveston Bay, Journal of the Waterways and Harbors Division, Proceedings of the American Society of Civil Engineers, 94(WW1), 33-57.

Taylor, G.I. (1921): Tidal oscillations in gulfs and rectangular basins, P. Lond. Math. Soc., 20, 193-204.

\title{
SAŽETAK
}

\section{Plimne oscilacije u sjevernom Jadranu: opažanja, modeliranje varijacijskom asimilacijom podataka i linearna plimna dinamika}

\author{
Jeffrey W. Book, Henry Perkins i Mark Wimbush
}

Petnaest vremenskih nizova mjerenja plimnih struja i pridnenih tlakova na otvorenom moru, $u$ razdoblju duljem od šest mjeseci, predstavlja novu bazu podataka za plimne oscilacije sjevernog Jadrana. Opažanja pokazuju gotovo obrat plimnih struja na većini lokacija i povećanje njihove snage u blizini Istre. Amplitude plimnih denivelacija povećavaju se prema sjeverozapadu a faze rastu u smjeru suprotno od kazaljke na satu, jako za poludnevnu komponentu, slabo za dnevnu. Podaci su upotrijebljeni za optimalno određivanje rubnih uvjeta $u$ linearnom modelu koji je korišten kao strogi uvjet $u$ varijacijskoj asimilaciji. Dobiveno srednje kvadratno odstupanje za plimne denivelacije je manje od $1 \mathrm{~cm}$, a za plimne struje manje je od $0.5 \mathrm{~cm} / \mathrm{s}$. Izračunati $Q$-faktori za model su 14.0 za $M_{2}$ komponentu i 22.4 za $K_{1}$ komponentu, ali usporedbe između disipacije trenjem procijenjene iz modela i iz mjerenja sugerira da su vrijednosti disipacije $u$ modelu prevelike za faktor 2 , te da su vrijednosti $Q$ faktora premale. Modelirana potencijalna energija je 1.5 puta veća od kinetičke energije za $M_{2}$ komponentu i 6.1 
puta veća od kinetičke energije za $K_{1}$ komponentu. Rezultati mjerenja i modela sugeriraju da protoci energije iz Kvarnerskog zaljeva daju značajan doprinos ravnoteži plimne energije u sjevernom Jadranu. Protoci energije $M_{2}$ komponente podržavaju koncept upadnog i reflektiranog Kelvinovog vala u sjevernom Jadranu uz neke modifikacije. Protoci energije $K_{1}$ komponente pokazuju poprečni tok u smjeru sjeveroistoka u blizini $50 \mathrm{~m}$ izobate gdje je nagib dna osobito strm, sa strukturama sličnima Kelvinovom valu sjeverno od grebena i odstupanja od Kelvinovog vala južno od grebena.

Ključne riječi: brzina plimnih struja, plimne denivelacije, disipacija plimne energije, Kelvinov val, topografski Rossbyjev val, protok energije

Corresponding author's address: Jeffrey W. Book, Naval Research Laboratory, Stennis Space Center, MS 39529-5004, U.S.A., tel.: + 1 228-688-5251, fax: +1 228-688-5997, e-mail: book@nrlssc.navy.mil 